\title{
A systematic review on poly(l:C) and poly- ICLC in glioblastoma: adjuvants coordinating the unlocking of immunotherapy
}

Jorrit De Waele ${ }^{1 *} \mathbb{D}$, Tias Verhezen ${ }^{1}$, Sanne van der Heijden ${ }^{1}$, Zwi N. Berneman ${ }^{2,3,4}$, Marc Peeters ${ }^{1,5}$, Filip Lardon', An Wouters $^{1+}$ and Evelien L. J. M. Smits ${ }^{1,4+}$

\begin{abstract}
Immunotherapy is currently under intensive investigation as a potential breakthrough treatment option for glioblastoma. Given the anatomical and immunological complexities surrounding glioblastoma, lymphocytes that infiltrate the brain to develop durable immunity with memory will be key. Polyinosinic:polycytidylic acid, or poly(l:C), and its derivative poly-ICLC could serve as a priming or boosting therapy to unleash lymphocytes and other factors in the (immuno)therapeutic armory against glioblastoma. Here, we present a systematic review on the effects and efficacy of poly(l:C)/poly-ICLC for glioblastoma treatment, ranging from preclinical work on cellular and murine glioblastoma models to reported and ongoing clinical studies. MEDLINE was searched until 15 May 2021 to identify preclinical (glioblastoma cells, murine models) and clinical studies that investigated poly(l:C) or poly-ICLC in glioblastoma. A systematic review approach was conducted according to PRISMA guidelines. ClinicalTrials.gov was queried for ongoing clinical studies. Direct pro-tumorigenic effects of poly(l:C) on glioblastoma cells have not been described. On the contrary, poly $(I: C)$ changes the immunological profile of glioblastoma cells and can also kill them directly. In murine glioblastoma models, poly(l:C) has shown therapeutic relevance as an adjuvant therapy to several treatment modalities, including vaccination and immune checkpoint blockade. Clinically, mostly as an adjuvant to dendritic cell or peptide vaccines, poly-ICLC has been demonstrated to be safe and capable of eliciting immunological activity to boost therapeutic responses. Poly-ICLC could be a valuable tool to enhance immunotherapeutic approaches for glioblastoma. We conclude by proposing several promising combination strategies that might advance glioblastoma immunotherapy and discuss key pre-clinical aspects to improve clinical translation.
\end{abstract}

Keywords: Poly(l:C), Poly-ICLC (Hiltonol), Glioblastoma, Immunotherapy, Immune checkpoint, Vaccination, Combination therapy, Toll-like receptor 3, Adjuvant, Glioma

\footnotetext{
* Correspondence: jorrit.dewaele@uantwerpen.be

${ }^{\dagger}$ An Wouters and Evelien L.J.M. Smits share senior co-authorship.

'Center for Oncological Research (CORE), Integrated Personalized \& Precision

Oncology Network (IPPON), University of Antwerp, Universiteitsplein 1,

B-2610 Antwerp, Belgium

Full list of author information is available at the end of the article
}

(c) The Author(s). 2021 Open Access This article is licensed under a Creative Commons Attribution 4.0 International License, which permits use, sharing, adaptation, distribution and reproduction in any medium or format, as long as you give appropriate credit to the original author(s) and the source, provide a link to the Creative Commons licence, and indicate if changes were made. The images or other third party material in this article are included in the article's Creative Commons licence, unless indicated otherwise in a credit line to the material. If material is not included in the article's Creative Commons licence and your intended use is not permitted by statutory regulation or exceeds the permitted use, you will need to obtain permission directly from the copyright holder. To view a copy of this licence, visit http://creativecommons.org/licenses/by/4.0/ The Creative Commons Public Domain Dedication waiver (http://creativecommons.org/publicdomain/zero/1.0/) applies to the data made available in this article, unless otherwise stated in a credit line to the data. 


\section{Background}

Glioblastoma (GBM) is the most common primary brain tumor and remains one of the deadliest cancers to date. The contemporary first-line multimodal standard of care (SOC), as defined by the landmark 2005 EORTC TMZ trial [1], consists of maximal surgical resection followed by chemoradiation and adjuvant temozolomide (TMZ), but it only renders a 14.6-month median overall survival (mOS) and a 7.2\% five-year survival [1, 2]. Major therapeutic hurdles include incomplete surgical resection, due to the invading nature of GBM, and therapeutic resistance, due to refractory cells in the heterogenous GBM cell population. Inevitably, recurrence occurs, at which point a patient's only option are salvage treatment modalities, which are often experimental with limited efficacy [3]. With the current SOC having "celebrated" its $15^{\text {th }}$ anniversary last year, it is evident that the therapeutic landscape for GBM is unquestionably in dire need of rejuvenation with novel and effective treatment options.

Immunotherapy for GBM treatment is intensively under investigation as the immune system theoretically possesses proficient features against the heterogeneous nature of GBM. However, GBM has adapted an immunosuppressive state which will have to be conquered [4]. The aim of immunotherapy is to enable immune cells to recognize and eradicate refractory GBM cells, while developing memory to prevent tumor recurrence. Multiple avenues to achieve this are being pursued, including dendritic cell (DC) vaccination, immune checkpoint blockade (ICB), chimeric antigen receptor (CAR) $\mathrm{T}$ cells and oncolytic viruses [4]. In this review, we focused on polyinosinic:polycytidylic acid or poly(I:C), and its derivative stabilized with carboxymethylcellulose and poly-L-lysine (poly-ICLC), adjuvants included on the Cancer Immunotherapy Trials Network's priority list of agents to boost cancer immunotherapy. Both poly(I:C) and poly-ICLC hold great potential to becoming pivotal, adjuvant components in the multifaceted immunotherapy approach to GBM.

Poly(I:C) and poly-ICLC are synthetic double-stranded RNA molecules (dsRNA) consisting of a polyinosinic acid homopolymer annealed to a polycytidylic acid homopolymer, thus resulting in a stable double helix [5] They bind to endosomal Toll-like receptor (TLR)-3 and the cytoplasmic receptors retinoic acid-inducible gene I (RIG-I) and melanoma differentiation-associated gene 5 (MDA-5) [6], as shown in Fig. 1. As such, they mimic a viral infection, consequently eliciting the secretion of type I interferon (IFN) and pro-inflammatory cytokines, which play prominent roles in inducing an immune response [6]. TLR-3 and MDA-5/RIG-I both elicit their signaling function via recruitment of an adaptor protein, TLR adaptor molecule 1 (TICAM1) and the mitochondrial antiviral signaling protein (MAVS), respectively. Both pathways converge to tumor necrosis factor (TNF) receptorassociated factors TRAF3 and TRAF6. TRAF3 leads to complexation of TBK1, TRAF family member-associated nuclear factor $\mathrm{k}$-light-chain-enhancer of activated B cells $(\mathrm{NFkB})$ activator binding kinase 1 , and inhibitor of $\mathrm{NF \kappa B}$ kinase subunit $\varepsilon(\mathrm{IKK} \varepsilon)$. This complex phosphorylates IFN regulatory factor 3 (IRF3) dimer, which then binds onto IFN-stimulated response element 3 (IRSE-3) following nuclear translocation. This leads to transcription of type I IFN, in particular IFN- $\beta$, as well as genes coding for lymphocyte trafficking molecules. TRAF6, in concert with receptor-interacting serine/threonine-protein kinase 1 (RIP1), leads to a transforming growth factor (TGF)- $\beta$ activated kinase 1 (TAK1) complex that phosphorylates two downstream pathways. On the one hand, the IKK $\alpha / \beta / \gamma$ complex relieves $\mathrm{NF} \kappa \mathrm{B}$ from its suppressor $\mathrm{NF} \mathrm{KB}$ inhibitor $\alpha$, allowing nuclear translocation. On the other hand, phosphorylation of mitogen-activated protein kinases (MAPK) leads to activation of activator protein 1 (AP-1). Both NFkB and AP-1 generate pro-inflammatory cytokines and chemokines [6-8]. Although the endosomal and cytoplasmic receptors signal through similar pathways, some distinctions exist. While TLR-3 activation favors pro-inflammatory cytokines, the endosomal receptors are more inclined to produce type I IFN, with IRF7 activation more readily in the picture, and interleukin (IL)-15 [9]. Also the formulation of dsRNA influences the outcome. Poly(I:C) more activates TLR-3, with the cytoplasmic receptors being activated following endosomal leakage and bearing a preference for high (MDA-5) or low molecular weight (RIG-I) poly(I:C) $[10,11]$. Poly-ICLC, by virtue of the components that stabilize poly(I:C), results in stronger activation of cytoplasmic receptor signaling by virtue of endosomal rupture due to the components to stabilize poly(I:C) $[9,11]$.

Due to its capacity to activate many immune cell types directly and indirectly, as depicted in Fig. 2, poly(I:C) is distinctly known for its immunostimulatory activity [12]. In this context, it is primarily renowned as a priming agent for activating antigen-presenting cells, in particular dendritic cells (DC) [13]. Indeed, poly(I:C) activates DC to strongly upregulate signals required for antigenspecific T-cell priming, as depicted in Fig. 2, which include: co-stimulatory molecules CD80, CD86 (signal 2) and CD40; pro-inflammatory cytokines such as IL-12 (signal 3); and, chemokines that attract $\mathrm{T}$ cells, e.g. CXCL10 [13-15]. Furthermore, poly(I:C) treatment of $\mathrm{DC}$ in a booster phase stimulates secondary T-cell expansion to a much greater extent than other TLR agonists, through type I IFN and IL-15 signaling $[9,16]$. Therefore, poly(I:C) has regularly been used in DC maturation protocols in vitro in order to obtain efficient DC products, outperforming TLR-4 agonist LPS and a proinflammatory cytokine cocktail [13]. Moreover, in mice, 


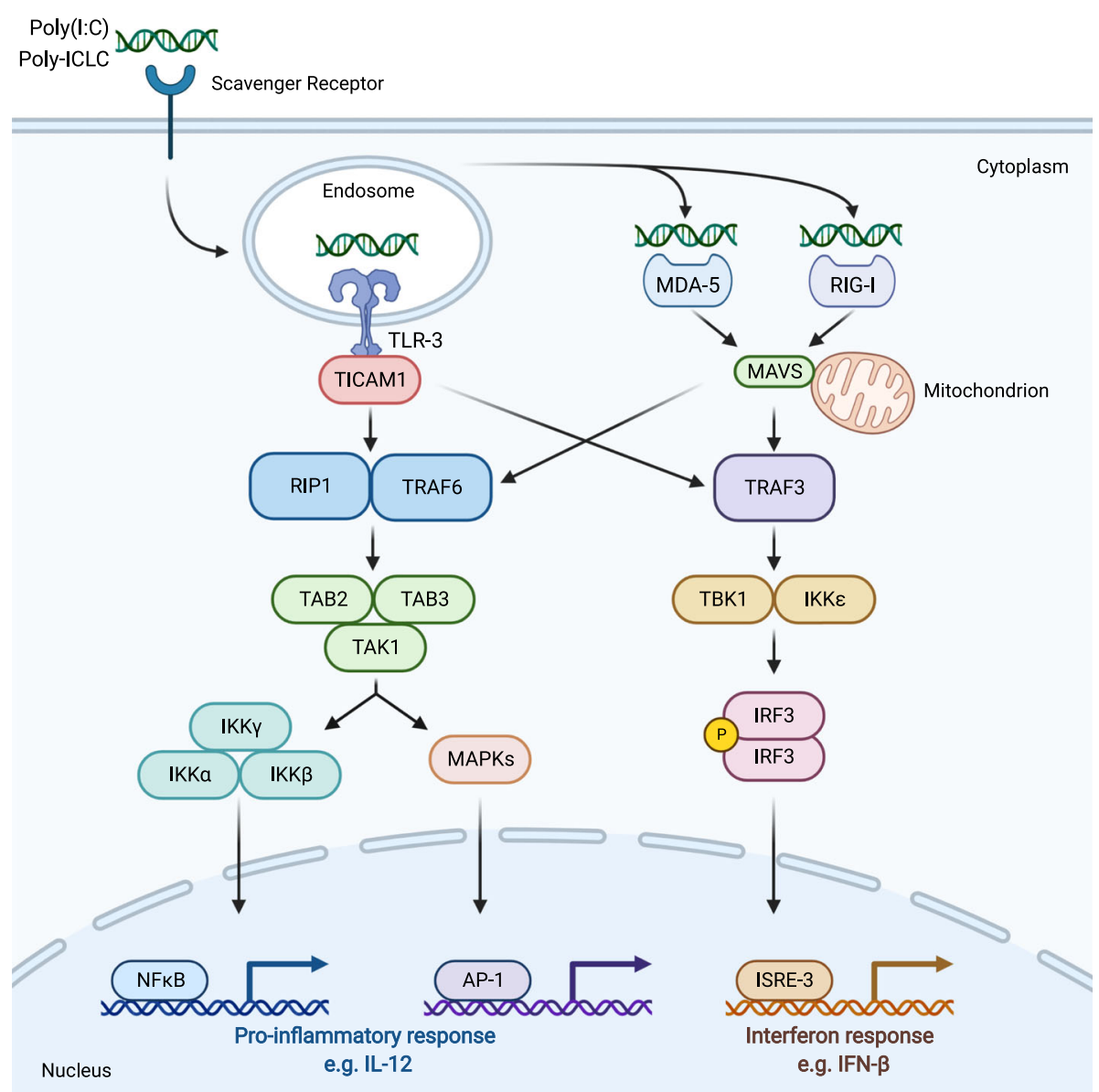

Fig. 1 Poly(l:C) and poly-ICLC signaling through TLR-3, MDA-5 and RIG-I generates a pro-inflammatory and interferon response. Poly(l:C) and polyICLC bind either the endosomal receptor TLR-3, leading to recruitment of adaptor molecule TICAM1, or the cytoplasmic receptors MDA-5 or RIG-I, which signal through the mitochondrial MAVS adaptor protein. Downstream both TICAM1 and MAVS transduce similar signal pathways via TRAF3 and TRAF6, though with distinct emphasis. TRAF3 leads to TBK1-IKKE complex formation, which results in phosphorylation of an IRF3 dimer that will induce an IFN response via IRSE3. TRAF6, along with RIP1, complexes TAK1 with TAB2 and TAB3, activating MAPK to activate transcription factor AP-1. The TAK1 complex will also activates the IKKa/B/ $/$ complex, allowing transcription of NFKB. Both AP-1 and NFKB results in proinflammatory cytokines and chemokines. Hence, poly $(\mathrm{I}: \mathrm{C})$ and poly-ICLC signaling result in an immunostimulatory response. AP-1, activator protein 1; IFN, interferon; IKKa $/ \beta / \gamma$, inhibitor of NFKB kinase regulatory subunit $\alpha / \beta / \gamma ; \mathrm{IL}-12$, interleukin-12; IRF3, IFN regulatory factor 3 ; ISRE-3, IFNstimulated response element 3; MAPKs, mitogen-activated protein kinases; MAVS, mitochondrial antiviral signaling protein; MDA-5, melanoma differentiation-associated gene 5; NFkB, nuclear factor k-light-chain-enhancer of activated B cells; Poly(l:C), polyinosinic:polycytidylic acid; PolyICLC, poly(I:C) stabilized with carboxymethylcellulose and poly-L-lysine; RIG-I, retinoic acid-inducible gene I; RIP1, receptor-interacting serine/ threonine-protein kinase 1; TAB, TAK1-binding protein; TAK1, transforming growth factor $\beta$ activated kinase 1; TBK1, TRAF family member associated NFKB activator binding kinase 1; TICAM1, TLR adaptor molecule 1; TLR-3, Toll-like receptor 3; TRAF; tumor necrosis factor receptor associated factor 3

poly(I:C) is the most effective inducer of type I IFN among TLR agonists [17]. In addition, poly(I:C)-treated DC activate natural killer (NK) cells through both IL-12 secretion and cell-cell contact [18]. Direct activation of NK cells by poly(I:C) has been reported as well, although reported data is conflicting $[19,20]$. Next to DC, poly(I: C) also profoundly affects macrophages, in a similar way. Interestingly, while it has been reported to repolarize M2 and tumor-associated macrophages (TAM) with tumoricidal and enhanced phagocytic capacities, it can also attract and stimulate $\mathrm{T}$ cells [21-23]. In addition to its effects on immune cells, poly(I:C) also affects other cells in the tumor microenvironment (TME). It has been shown to directly inhibit tumor growth via suppression of proliferation and induction of apoptosis in several tumor types [12]. Indeed, its viral mimicry can activate pathways to protect neighboring cells from infection, potentially culminating in cellular suicide [24]. Therefore, poly(I:C) is generally seen as a cytotoxic agent for tumor cells, but few studies reporting poly(I:C)-mediated stimulation of cancer cell migration, urge caution in its use $[25,26]$. Indeed, invasion of GBM cells into healthy 


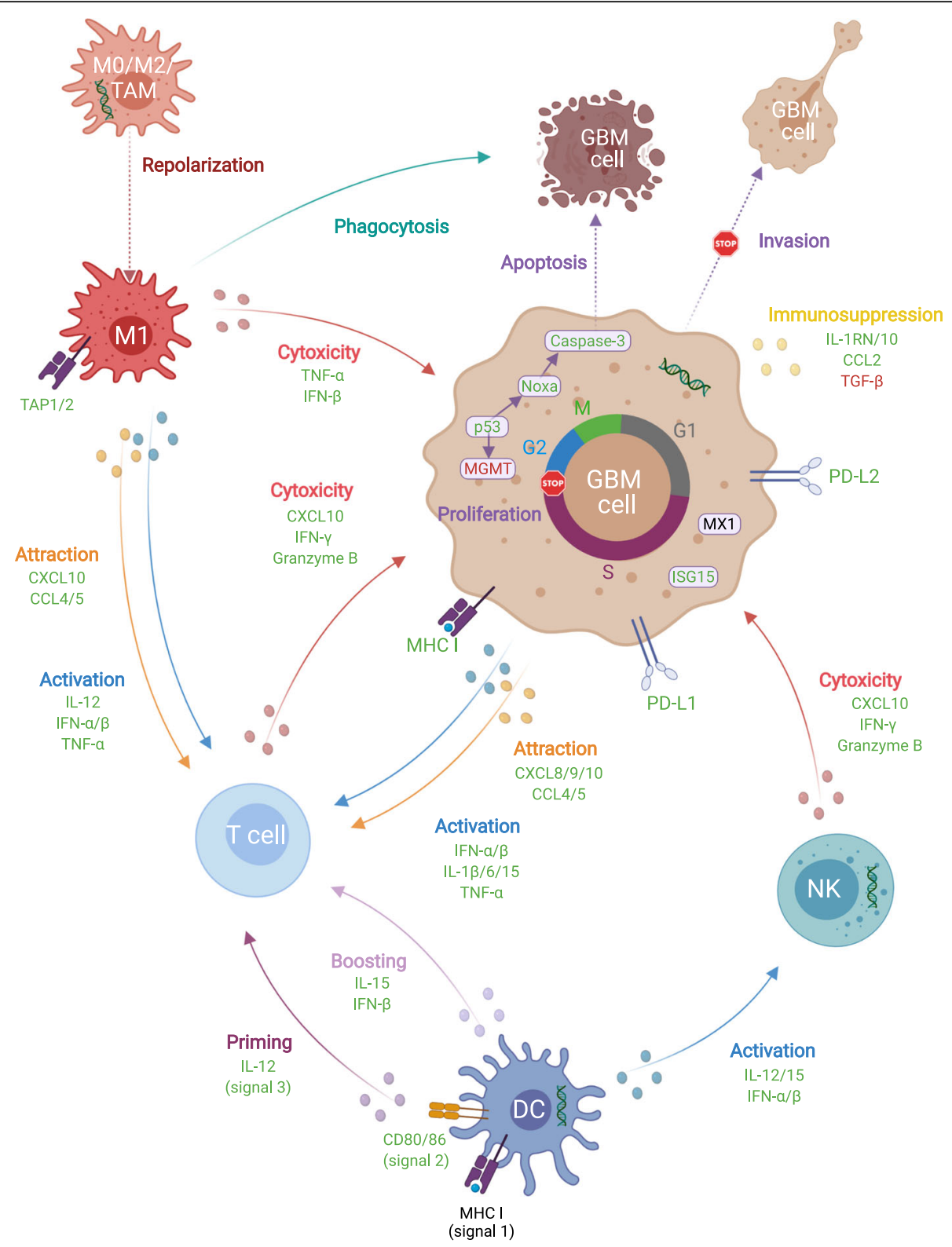

Fig. 2 Integrated overview on how poly(l:C) affects GBM and immune cells on molecular and functional levels. Poly(l:C) activates several immune cells directly and indirectly, while also leveraging the GBM cellular machinery for attraction and activation of immune cells. In addition, poly(l:C) can induce cytostasis, apoptosis and less invasiveness, while remaining sensitivity to certain viruses. Color coding of proteins indicates effect of poly(l:C) compared to non-treated cells: black, unaltered; green, upregulation/induction; red, downregulation/inhibition. Green helices represent double-stranded poly(l:C); small spheres represent secreted factors. CCL/CXCL, C-C/C-X-C motif chemokine ligand; GBM, glioblastoma; IFN, interferon; IL, interleukin; IL-1RN, IL-1 receptor antagonist; ISG15, IFN-stimulated gene 15; M0/1/2, M0/1/2-polarized macrophage; MGMT, O6methylguanine-DNA methyltransferase; MHC, major histocompatibility complex; MX1, MC dynamin-line GTPase 1; NK, natural killer cell; Noxa, phorbol-12-myristate-13-acetate-induced protein 1; PD-L, programmed death 1 ligand; poly(l:C), polyinosinic:polycytidylic acid; TGF, transforming growth factor; TAM, tumor-associated macrophage; TAP1/2, transporter 1/2, ATP binding cassette subfamily B member; TNF, tumor necrosis factor

parenchyma impedes surgical resection and paves the way for tumor recurrence. Therefore, poly $(\mathrm{I}: \mathrm{C})$ must be studied in the context of each tumor type. Here, we conducted a systematic review to evaluate the state-of-theart regarding the effects of poly(I:C) and poly-ICLC in GBM in order to evaluate its potential to boost immunotherapy for GBM. First, we examined in vitro studies to provide an overview of the direct effects of poly(I:C) on GBM cells. Next, we assessed pre-clinical in vivo studies, which also take into account the direct and indirect actions of poly(I:C) on neighboring stromal and peripheral immune cells. Afterwards, we described 
clinical experiences with poly-ICLC in GBM while looking ahead to trials currently ongoing. Finally, we concluded with a discussion on its position in the medical landscape for GBM and postulate future perspectives.

\section{Methods}

We executed a systematic review according to the Preferred Reporting Items for Systematic Review and MetaAnalyses (PRISMA) guidelines [27], as depicted in Fig. 3A. The search was conducted in the MEDLINE database (1973-present) using the terms displayed in Fig. 3B, ending on 15 May 2021. Research articles with data on poly(I:C) or poly-ICLC in GBM were included provided a full-text written in English was available. Reviews and perspectives were excluded, as well as articles that (i) did not use poly(I:C)/poly-ICLC, (ii) did not utilize
GBM as target tumor model, (iii) presented nonspecified or ambiguously-described in vitro effects of poly(I:C)/poly-ICLC, (iv) did not administer poly(I:C)/ poly-ICLC directly to test objects in studies in vivo, or (v) only reported on poly(I:C)/poly-ICLC-induced cellular signaling. We did not include other poly(I:C) derivatives, Ampligen (latest report in 1991) and BO-112 (novel and not yet tested in GBM). In addition, we searched for ongoing clinical trials with poly-ICLC on clinicaltrials.gov, using the strategy presented in Fig. 3C, which ended on 27 December 2020.

\section{In vitro effect of poly(l:C) on GBM cells}

Since poly $(\mathrm{I}: \mathrm{C})$ is primarily known in an immunological context, we first discuss the observations regarding interactions of GBM cells with the immune system
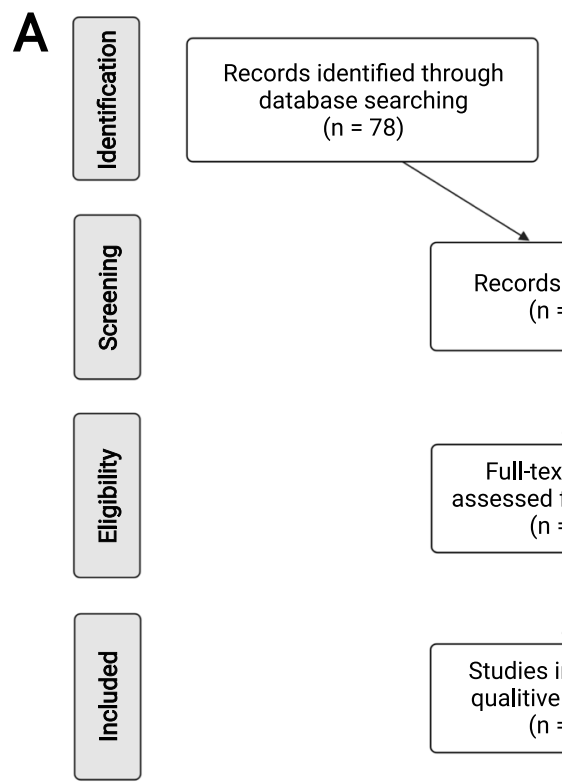
$(n=78)$
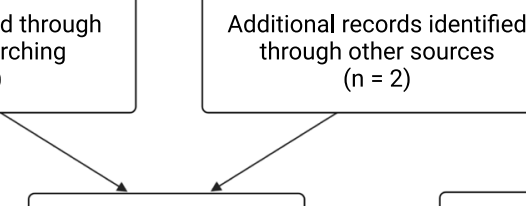
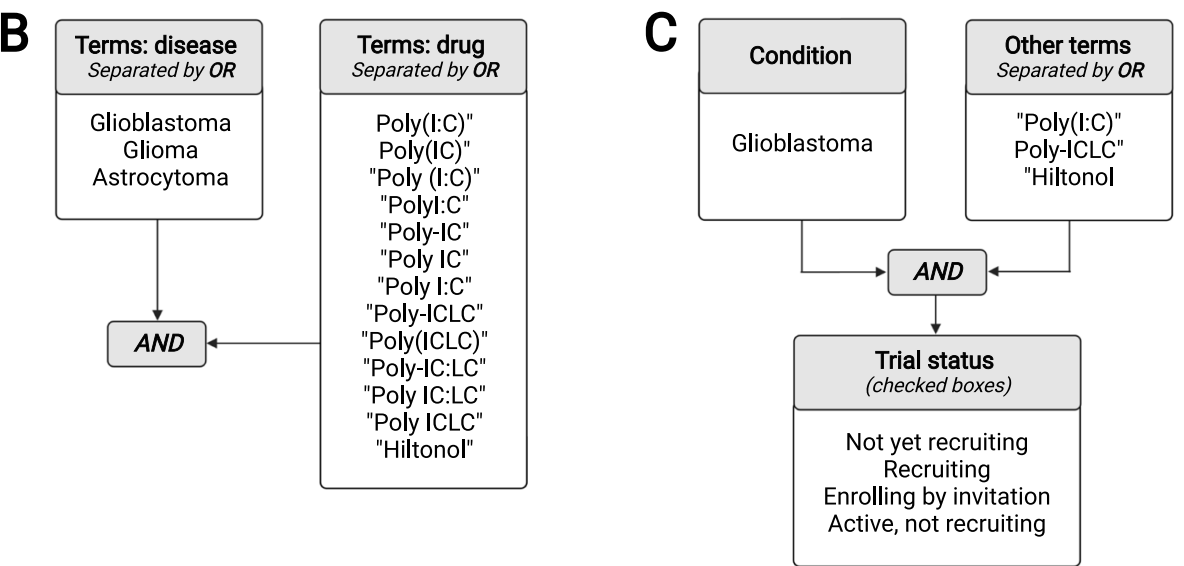

Fig. 3 Search strategies and assessment pipeline of systematic search. (A) PRISMA flow hart depicting the systematic assessment. (B-C) Search term applied to MEDLINE and clinicaltrials.gov, respectively. AND and OR represent Boolean operators 
following poly(I:C) treatment. Cell health as a direct target of poly $(\mathrm{I}: \mathrm{C})$ is subsequently discussed. Figure 2 presents an integrated response of GBM and immune cells to poly(I:C) and resulting (inter)cellular effects.

\section{Immunomodulation}

Although predominantly associated with poly(I:C)-mediated immune cell activation, poly(I:C)/poly-ICLC also induces type I IFN gene transcription and subsequent secretion of IFN- $\alpha$ and IFN- $\beta$ by both human and murine GBM cells [28-40]. Surprisingly, poly(I:C) did not initiate IFN- $\beta$ transcription in $\mathrm{C} 6$ rat glioma cells and some human GBM cell lines [41, 42]. In contrast, primary human GBM (pGBM) cells induced much stronger IFN- $\beta$ secretion compared to IFN- $\alpha$, while type II IFN- $\gamma$ secretion was absent [30]. Of note, two reports showed a stronger IFN- $\beta$ secretion upon targeting poly(I:C) to its cytosolic receptors rather than to TLR-3 [28, 31], suggesting that the robustness of the poly(I:C)-induced type I IFN response might depend on which receptor pathway is primarily targeted. Nonetheless, promoting endocytosis in murine GBM cells also elevated IFN- $\beta$ secretion [40]. Besides type I IFN, poly(I:C) also characteristically induces a release of pro-inflammatory cytokines [6]. This has also been the case in GBM cells, as evidenced by upregulated TNF- $\alpha$, IL- $1 \beta$, IL- 6 and IL- 15 [29, 30, 43-46]. Interestingly, poly(I:C) also downregulates the secretion of the strongly immunosuppressive TGF- $\beta$ [30], although it did increase the release of IL-1R antagonist and IL-10 [23]. A poly(I:C)-induced secretome favoring immunostimulation could lead to immune activation. Indeed, two studies reported immune activation by poly(I:C)-treated pGBM cells. Glas et al. observed a modest increase in type I IFN-dependent degranulation and cytolysis by NK cells, when cocultured with primary GBM stem cells (pGSC) treated with poly-ICLC or transfected poly(I:C) [31]. On the other hand, we demonstrated a significant increase of activated lymphocytes, releasing IFN- $\gamma$ and granzyme $\mathrm{B}$, when they were cocultured with untransfected poly(I:C)treated pGBM cells [30].

Similar to the induction of pro-inflammatory cytokines, poly(I:C) elicits the secretion of chemokines from GBM cells which can attract tumorlytic lymphocytes. Poly(I:C)/poly-ICLC, targeted to either receptor pathway, stimulates GBM cell secretion of CXCL8, CXCL9, CXCL10, CCL2, CCL4 and CCL5 [29-34, 37-40, 45]. In transwell assays using supernatant of poly(I:C)-treated pGBM, chemoattraction of $\mathrm{CD}^{+}$and $\mathrm{CD}^{+} \mathrm{T}$ cells, but not NK cells, was increased in a manner that suggested involvement of those ligands for CCR5 and CXCR3 [30].

While cytokines can signal from afar, interactions between membrane proteins on GBM and immune cells are central in dictating immunological activity. For $\mathrm{T}$ cells in particular, antigen presentation via major histocompatibility complex (MHC) molecules is crucial in their antigen-specific adaptive capacity [47]. Poly(I:C)/ poly-ICLC treatment of human and murine GBM upregulates MHC class I molecules, partly via treatmentinduced IFN- $\beta$ [39, 44, 48]. This suggests that poly(I:C)treated GBM cells bear enhanced epitope-presenting capacity for infiltrating $\mathrm{T}$ cells. On the other hand, MHC class I molecules can also signal inhibition of NK cells [49]. Nonetheless, it has been shown that NK cells become activated by poly(I:C)-treated pGBM cells and exert their lytic function [30,31], indicating that other factors tip the balance towards antitumoral activity.

In the last decade, there has been an impetus on immunotherapy given the clinical responses achieved by ICB in multiple cancer types [50]. Interestingly, low levels of programmed cell death 1 ligand (PD-L) 1 and PD-L2 expression on pGBM cells increase robustly, following untransfected poly(I:C) treatment, partly via downstream IFN- $\beta$ [30]. Although elevated immune checkpoint ligand expression would impair PD- $1^{+}$activated lymphocytes, immune activation was observed in cocultures with poly(I:C)-treated pGBM cells [30]. However, additional blockade of PD-L1 further propagated this immune activation. Intriguingly, such enhancement was not detected upon blocking PD-L2, suggesting that this ligand is redundant in GBM-mediated inhibition of immune cell activation [30]. This underscores the potential of targeting these negative feedback counter mechanisms to further invigorate anti-tumor immunity. Moreover, heightened PD-L1/PD-L2 expression is expected with immune activation due to immune cellsecreted IFN- $\gamma[30]$.

In summary, poly $(\mathrm{I}: \mathrm{C})$ - either untransfected, transfected, nanoplexed or in its stabilized form - induces secretion of pro-inflammatory cytokines and chemokines by pGBM cells, which are capable of eliciting in vitro immune attraction and activation. In addition, it demonstrates potency to prime GBM for T-cell immunity when combined with PD-1/PD-L1 blockade; NK cells could also play a role despite the presence of inhibitory signals.

\section{Viral sensitivity}

Oncolytic viruses are actively being evaluated in clinical trials for GBM (Clinicaltrial.gov: fifteen active and seven completed trials), with first results pointing towards a favorable safety profile and immunogenic activity [51]. While poly(I:C) did not affect the susceptibility of U87 cells, it protected normal human brain cells from viral infection, replication and induced cell death [42, 52]. Protection against VSV-rp30a is possibly conferred by MX1, a cellular antiviral protein that is profoundly induced by poly(I:C) in normal brain cells but barely modulated in GBM cells $[40,42]$. These observations argue 
for the adjuvant use of poly(I:C) in oncolytic virotherapy in order to protect healthy brain cells, though protection should be established upfront. Indeed, poly(I:C) also upregulates ISG15 in both normal brain cells and GBM cells, arguing against the use of e.g. Sindbis virus [42]. In addition, alternative formulations of poly(I:C) might induce MX1 in GBM cells [40], and therefore, the formulation is also of importance in this context.

\section{Cell health and behavior}

Central to cellular health are viability and proliferation as primary targets in cancer treatment. Poly(I:C)/polyICLC affects human GBM cell lines differently with regard to suppressing their growth, be it due to cytostatic or cytotoxic activities [28, 31, 42, 53-55]. Notably, no study observed stimulation of GBM cell proliferation. Discrepant findings were reported regarding poly(I:C) formulations most effective at mediating cytostasis/cytotoxicity. In an early study, the growth inhibitory effect was stronger for untransfected poly $(\mathrm{I}: \mathrm{C})$ in comparison to poly(I:C) entrapped in cationic liposomes [28]. In contrast, a more recent study demonstrated that transfected reduced the metabolic activity of (p)GBM cells while untransfected poly(I:C) did not. This was associated with induction of apoptosis through caspase- 3 and Noxa and mediated through MDA-5/RIG-I rather than TLR-3 [31]. Moreover, both pGBM/pGSC could be targeted with transfected poly(I:C), whereas several nonmalignant brain cell types remained unharmed [31]. Although upregulation of Noxa also occurred in these normal cells, its effect was presumably disarmed by the higher expression of the anti-apoptotic Bcl-2 [31]. Other studies found that transfection of pegylated poly(I:C) rapidly induced apoptosis, further enhanced by modifications that augment cytosolic release [54, 55].

In $\mathrm{C} 6$ rat glioma cells, poly(I:C) inhibits ligands, receptors and binding proteins of the insulin-like growth factor system, allowing poly(I:C)-induced IFN- $\alpha$ to mediate cytostasis [41, 56, 57]. Indeed, despite increased DNA synthesis and $\mathrm{S}$ phase being increased, a proliferative reduction was achieved due to an S/G2-driven cell cycle arrest. Cytotoxicity was only observed upon long-term culture in starved conditions [41].

Invasion of GBM in the surrounding healthy brain parenchyma presents a paramount problem to achieving complete resection without compromising neurological or motor functions of the patient. Treatment with poly $(\mathrm{I}: \mathrm{C})$ diminished invasion of human GBM spheroids embedded in a collagen matrix [22]. Although this effect was not observed with rat GBM spheroids, the absence of an enhanced invasive capacity is particularly important.

In conclusion, there are no indications that poly $(\mathrm{I}: \mathrm{C})$ mediates protumoral effects regarding GBM cell health and behavior. In contrast, it has proven to be cytostatic/ cytotoxic and potentially anti-invasive, but optimization of its formulation appears to be required to unlock its full potential.

\section{Effects of poly(I:C) in GBM animal models}

In particular for GBM, the existence of the blood-brainbarrier (BBB) imposes a unique complexity. Whereas we focused on the direct effects of poly(I:C)/poly-ICLC on GBM cells in the above chapter, here we elaborate on its general effect in animal GBM models.

\section{Safety}

To date, none of the preclinical in vivo GBM studies employing poly(I:C) have reported any adverse events (AE) or pathological defects regarding physical, behavioral or neurological characteristics; this includes both in immediate circumstances and in long-term surviving mice [28, 39, 44, 55, 58]. In addition, reports on exacerbation of GBM growth or invasiveness are absent. Hence, no observations indicate any concern for safety.

\section{Poly $(\mathrm{l}: \mathrm{C})$ as stand-alone treatment}

Intratumoral release of epidermal growth factor receptor-targeted pegylated (PEG) poly(I:C) via osmotic micropumps significantly extended the lives of U87 xenograft-implanted mice. Enhanced cytosolic release of PEG-poly(I:C) even completely eradicated large tumors [55]. In addition, bystander effects also killed unsusceptible cells in a mixed xenograft model, suggesting its applicability in heterogeneous tumors such as GBM [55].

In contrast, single-agent treatment with poly(I:C)/polyICLC failed to show a robust therapeutic effect in syngeneic CT-2A and GL261 models [39, 44, 58-60], even following tumor-targeted delivery [40], although surviving mice developed immune memory [59]. Nonetheless, poly(I:C) effectively enhanced activation of resident DC in the brain TME, while the number of non-migratory and migratory DC in the tumor-draining lymph nodes (dLN) decreased and increased, respectively. Furthermore, enhanced division of dLN-residing antigenspecific $T$ cells elevated the percentage of TNF- $\alpha^{+}$ antigen-specific $T$ cells in the brain [59], although tumor-infiltrating lymphocytes (TIL) remained scarce [40]. These observations in the brain and dLN suggest that poly(I:C) strengthens the potential for antigen presentation and development of an immune response, which notwithstanding remains largely incapacitated. For instance, poly(I:C) increased PD-L1 expression in the brain and on myeloid cells in dLN and spleen [40, 59]. Hence, these observations advocate for its use in immunotherapeutic combination regimens. In addition, the ability of poly(I:C)/poly-ICLC to produce a proinflammatory response was replicated in vivo across the 
BBB as demonstrated by the transient increase in serum and brain of TNF- $\alpha$ and IFN- $\alpha$, despite systemic administration $[39,58]$.

\section{Immune checkpoint blockade}

As it stands, poly(I:C) single-agent treatment appears to prime both tumor and immune microenvironments for antitumor immunity but is unable to single-handedly unleash it. In this regard, GBM cells and DC have been shown to counter the poly(I:C)-driven pro-inflammatory signature by upregulating immune checkpoint ligands PD-L1 and PD-L2 [30, 40, 59]. Consequently, poly(I:C) and anti-PD-1 therapy synergize to provide a great survival benefit including immune memory in the GL261 in vivo model [59]. This was accompanied by decreased myeloid and regulatory $\mathrm{T}$ cells (Treg) in the brain, which welcomed more non-migratory $\mathrm{DC}$ and $\mathrm{IFN}-\gamma^{+} \mathrm{CD} 8^{+} \mathrm{T}$ effector cells. In the dLN, more activated myeloid and memory $\mathrm{T}$ (Tmem) cells were observed. The therapeutic synergy was fully dependent on cross-presenting DC, demonstrating that this benefit was related to the activation of antigen presentation, the priming and expanding of antigen-specific effector T cells in the dLN and their subsequent brain infiltration. These events are all crucial set-points in the cancer-immunity cycle [47]. The combination treatment further increased myeloid PD-L1 expression in the dLN, whereas PD-L2 expression remained unaltered [59], supporting the in vitro observation that PD-L2 presumably plays no major role in GBM-mediated immunosuppression [30]. In conclusion, the individual potentials of both therapeutic arms become synergistically unlocked via a synchronized modulation of antigen presentation in the myeloid department.

\section{Vaccination}

Vaccination with glioma-associated antigen (GAA)loaded DC or GAA peptides represents a popular immunotherapeutic strategy. Both in prophylactic and therapeutic settings, poly-ICLC significantly increased longterm survival of GL261-bearing mice treated with GAA vaccines $[39,60]$. This was characterized by enhanced GAA-specific TIL, due to upregulated CXCL10 secretion in the TME, and development of immune memory [39, 60]. The combination strategy generates an IFN- $\gamma$ driven positive feedback loop (by lymphocytes) of the type I IFN polarization process (by tumor and myeloid cells) in the TME, causing a CXCL10 burst at the tumor site which is crucial for the recruitment of GAA-specific $\mathrm{T}$ cells [60]. Hence, poly-ICLC is critical for efficacious GBM vaccination. An addition of anti-CCL2 to inhibit tumor infiltration of immunosuppressive cells did not significantly improve survival further [61]. Interestingly, the distance from the tumor to the vaccination site appears correlated to therapeutic efficacy. The GBM tumor was able to prevent or suppress CTL priming when vaccinated in the cervical dLN or axillary LN, respectively, whereas a tumoricidal CTL response was only robustly develop by poly-ICLC-adjuvanted vaccination in the inguinal LN [62]. In summary, both poly-ICLC and vaccination site are critical determinants in GBM vaccination success.

\section{Other combinations}

In the nineties, the combination of poly(I:C) with cycloheximide resulted in IFN- $\beta$ production and tumor growth inhibition in GBM-bearing nude mice, which was further strengthened by targeting poly(I:C) to the cytosolic receptors via liposome entrapment [28]. Recently, the combination of poly(I:C) with a small molecule antagonist of the inhibitor of apoptosis (LCL161), also called a Smac mimetic compound, increased the $17 \%$ survival rate for each monotherapy to $86 \%$ in combination in CT-2A-bearing mice [58]. This synergy was based on the sensitizing effect of LCL161 to TNF- $\alpha$ induced tumor cell death in conjunction to induction of TNF- $\alpha$ secretion by poly(I:C). In addition, Smac mimetics block the growth-promoting activities of TNF- $\alpha$, rendering this an intriguing combination option [58]. Last year, Yin et al. reported the intranasal delivery of poly(I:C) bound to gold nanoparticles, as a means to bypass the BBB and target the tumor cells. This extended the survival of mice treated with the conventional drug TMZ. The authors postulated that the combination was required to induce a coordinated release of IFN- $\beta$ and killing of tumor cells by poly(I:C) and TMZ, respectively, resulting in immunogenic cell death (ICD) [40]. Given that TMZ remains SOC for newly-diagnosed GBM patients, this observation further encourages the inclusion of poly(I:C), as part of an immunotherapy, in the current treatment regimen for GBM.

\section{Clinical studies with poly-ICLC in GBM}

In the earlier clinical GBM studies poly-ICLC was used as stand-alone treatment or in combination with (chemo)radiation, but lately is has mostly been used as a GBM vaccine adjuvant. Below we discuss the reported clinical findings in humans. Our methodological search found thirteen peer-reviewed reports on eleven clinical studies, as shown in Table 1: four non-vaccination trials [63-66] and seven vaccination trials as adjuvant to DC (three) or peptides (four) [67-75]. Newly-diagnosed and/ or recurrent GBM were enrolled in four phase I, four phase I/II and three phase II trials. These studies enrolled a total of 323 patients, of which 227 suffered from GBM and another 21 from unspecified high-grade glioma (HGG). Only one study had a control arm for polyICLC [74]. Table 2 provides an overview of five currently ongoing trials. 


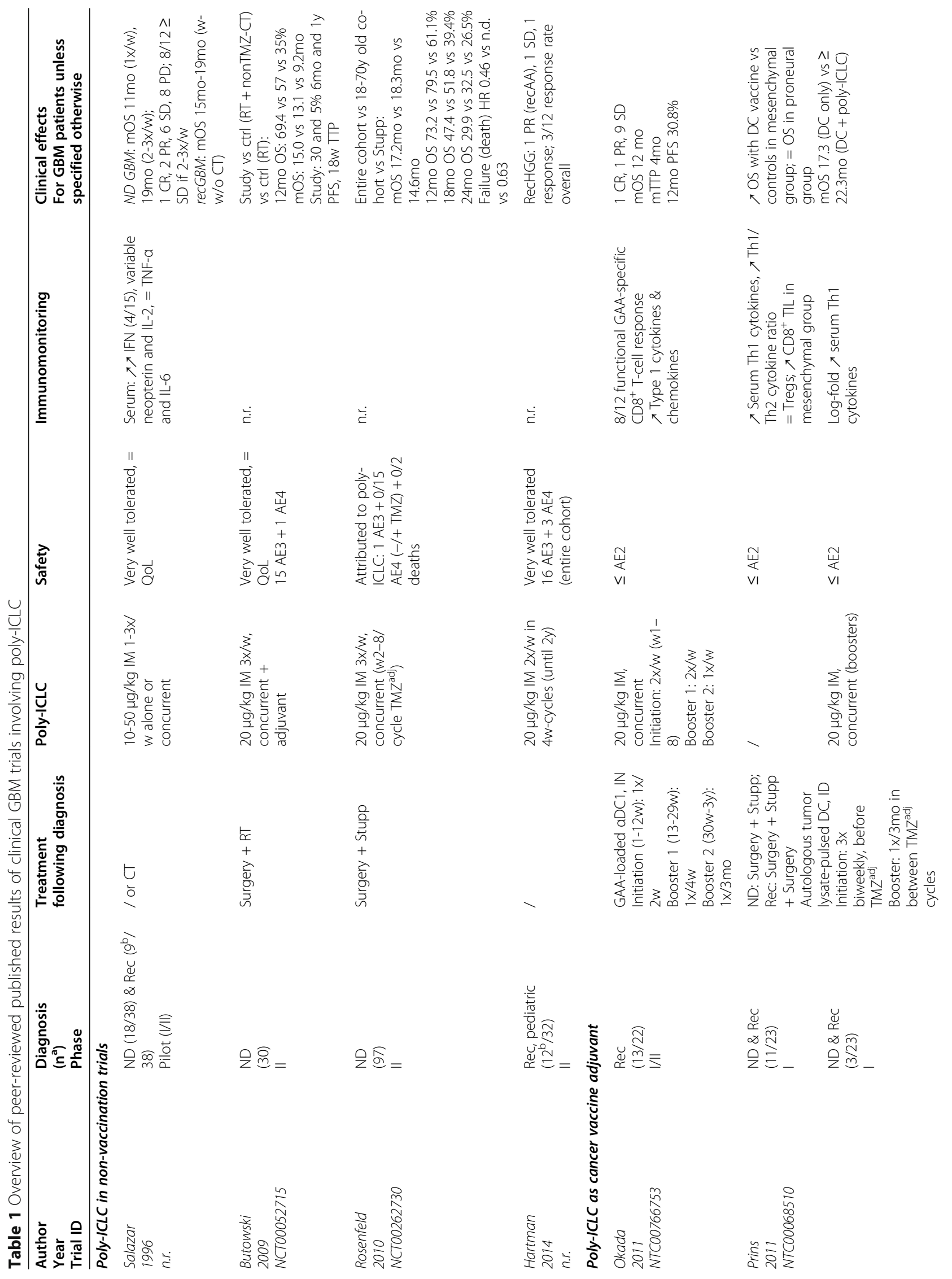




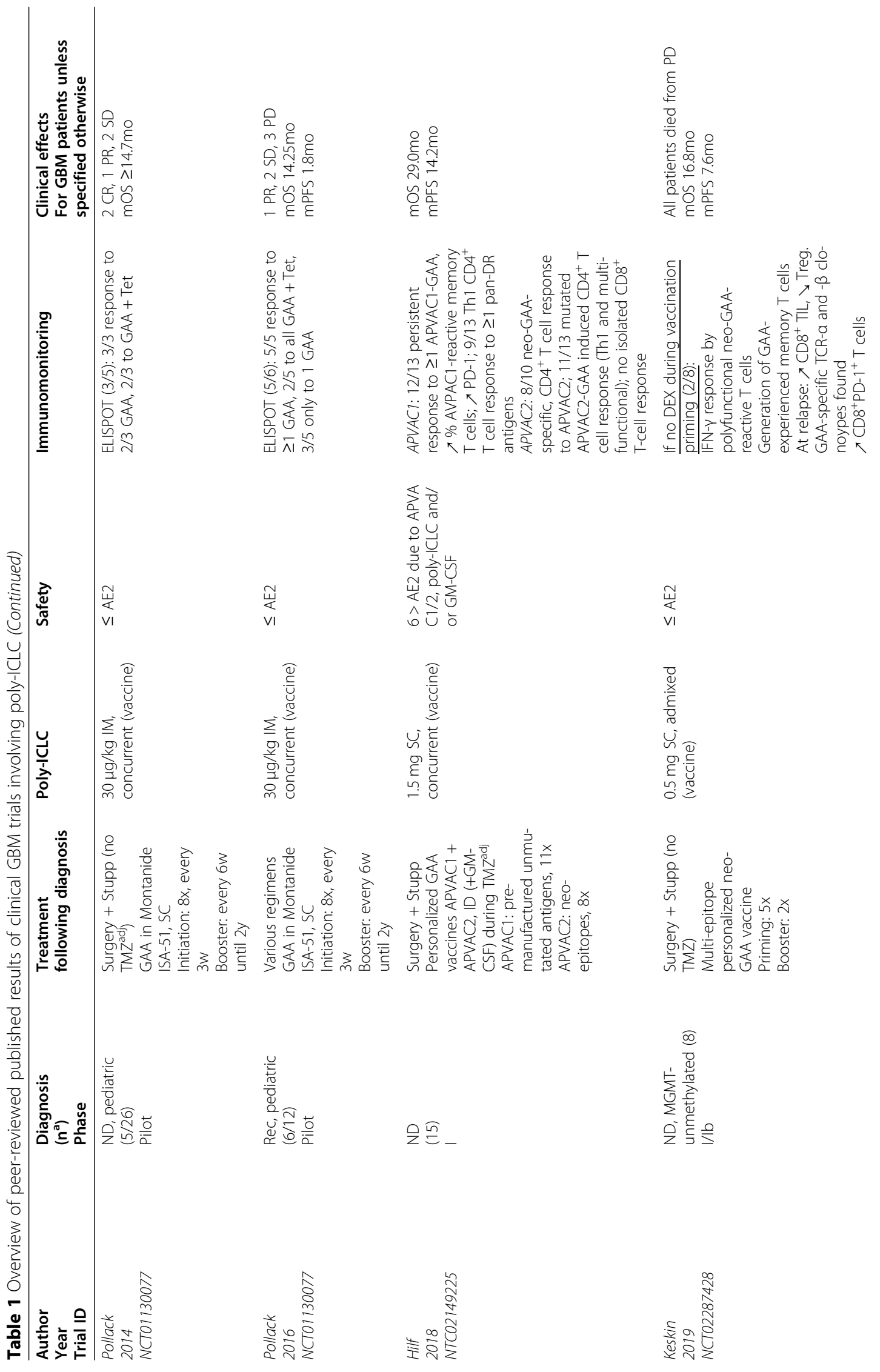




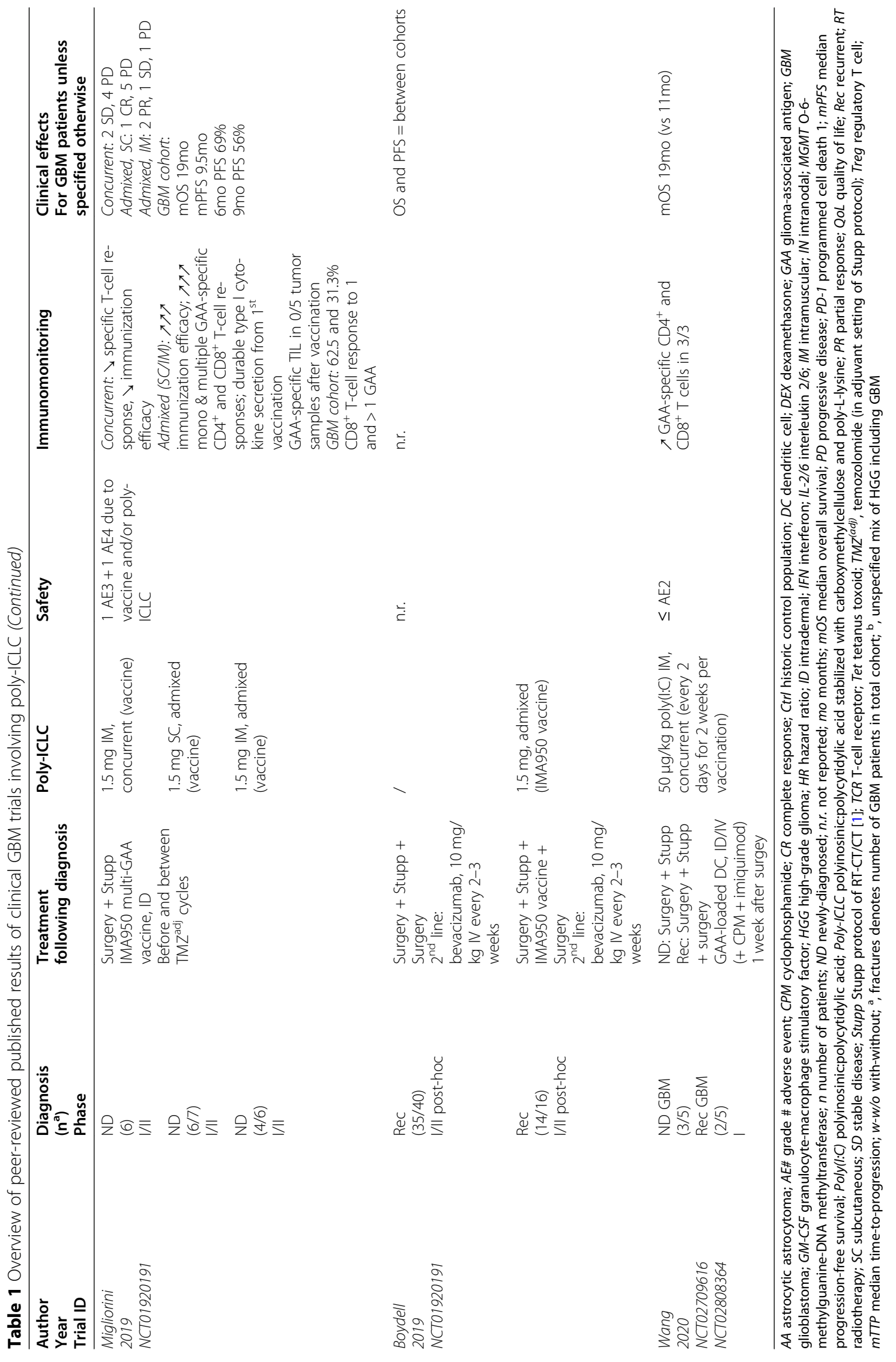


Table 2 Overview of ongoing clinical glioblastoma trials involving poly-ICLC

\begin{tabular}{|c|c|c|c|}
\hline $\begin{array}{l}\text { Trial ID } \\
\text { Phase }\end{array}$ & $\begin{array}{l}\text { Diagnosis } \\
\left(n^{\text {estim }}\right)\end{array}$ & Treatment following diagnosis & Poly-ICLC \\
\hline \multicolumn{4}{|l|}{ Ongoing trials } \\
\hline \multirow[t]{6}{*}{$\begin{array}{l}\text { NCT03422094 } \\
\text { I }\end{array}$} & \multirow[t]{6}{*}{$\begin{array}{l}\text { ND, unmethylated } \\
\text { (30) }\end{array}$} & $\begin{array}{l}\text { Surgery }+ \text { Stupp } \\
\text { Investigational procedure during TMZ }{ }^{\text {adj. }} \text { : } \\
\text { NeoVax, SC (4x priming in cycle } 1+1 \text { booster/cycle), + }\end{array}$ & \multirow[t]{6}{*}{$1.5 \mathrm{mg}$ SC, admixed (vaccine) } \\
\hline & & Nivolumab, 480 mg IV (start at progression) & \\
\hline & & Nivolumab, 480 mg IV (start with cycle 2) & \\
\hline & & Nivolumab, 480 mg IV (start with cycle 1) & \\
\hline & & $\begin{array}{l}\text { Nivolumab, } 480 \text { mg IV (start with cycle 3) } \\
\text { Ipilimumab, } 1 \text { mg/kg IV (cycle 1) }\end{array}$ & \\
\hline & & $\begin{array}{l}\text { Nivolumab, } 3 \text { mg/kg IV (2x/cycle) } \\
\text { Ipilimumab, } 1 \text { mg/kg IV (every } 6 \text { weeks) }\end{array}$ & \\
\hline \multirow{2}{*}{$\begin{array}{l}\text { NCT04201873 } \\
\text { I }\end{array}$} & \multirow{2}{*}{$\begin{array}{l}\operatorname{Rec} \\
(40)\end{array}$} & Surgery + ALT-DC vaccine ID & \multirow[t]{2}{*}{$\mathrm{IM}$, with vaccine } \\
\hline & & $\begin{array}{l}\text { Surgery + ALT-DC vaccine ID } \\
\text { Pembrolizumab, IV, neo-adjuvant to surgery }\end{array}$ & \\
\hline \multirow[t]{2}{*}{$\begin{array}{l}\text { NCT03223103 } \\
\mathrm{la} / \mathrm{lb}\end{array}$} & \multirow[t]{2}{*}{$\begin{array}{l}\mathrm{ND} \\
(20)\end{array}$} & $\begin{array}{l}\text { Surgery + Stupp } \\
\text { Investigational procedure during TMZ }{ }^{\text {adj: }} \text { : }\end{array}$ & \multirow[t]{2}{*}{$100 \mu \mathrm{g} /$ dose, with vaccine } \\
\hline & & $\begin{array}{l}\text { Mutation-derived GAA-based personalized vaccine } \\
\text { Tumor-treating fields (continuous) }\end{array}$ & \\
\hline \multirow{2}{*}{$\begin{array}{l}\text { NCT03665545 } \\
\text { I/II }\end{array}$} & \multirow{2}{*}{$\begin{array}{l}\operatorname{Rec} \\
(24)\end{array}$} & IMA950 vaccine, SC & \multirow[t]{2}{*}{ SC, admixed (vaccine) } \\
\hline & & $\begin{array}{l}\text { IMA950 vaccine, SC } \\
\text { Pembrolizumab, IV }\end{array}$ & \\
\hline \multirow{3}{*}{$\begin{array}{l}\text { NCT01204684 } \\
\|\end{array}$} & \multirow{3}{*}{$\begin{array}{l}N D^{a} \& \operatorname{Rec}^{a} \\
\text { (30) }\end{array}$} & Autologous tumor lysate-pulsed DC vaccine & / \\
\hline & & $\begin{array}{l}\text { Autologous tumor lysate-pulsed DC vaccine } \\
0.2 \% \text { resiquimod, concurrent (vaccine) }\end{array}$ & / \\
\hline & & Autologous tumor lysate-pulsed DC vaccine & Concurrent (vaccine) \\
\hline \multicolumn{4}{|c|}{ Completed trial, but no peer-reviewed report yet ${ }^{\complement}$} \\
\hline $\begin{array}{l}\text { NCT02078648 } \\
\text { ॥ }\end{array}$ & $\begin{array}{l}\operatorname{Rec} \\
\left(28^{b}\right)\end{array}$ & $\begin{array}{l}\text { SL-701 vaccine, biweekly } \\
10 \mathrm{mg} / \mathrm{kg} \text { bevacizumab, IV, concurrent (vaccine) }\end{array}$ & IM, concurrent (vaccine) \\
\hline
\end{tabular}

DC dendritic cell; GAA glioma-associated antigen; IM intramuscular; $I V$ intravenous; $n^{\text {estim }}$ estimated enrollment; $N D$ newly-diagnosed; Poly-ICLC polyinosinic:polycytidylic acid stabilized with carboxymethylcellulose and poly-L-lysine; Rec recurrent; SC subcutaneous; Stupp Stupp protocol of radiotherapy with concurrent and adjuvant chemotherapy [1]; $T M Z^{\text {adj }}$ temozolomide in adjuvant setting of Stupp protocol; ${ }^{\mathrm{a}}$, high-grade glioma including glioblastoma; ${ }^{\mathrm{b}}$, accrued number of patients; ${ }^{c}$, conference abstract available [76]

\section{Safety and administration route}

In the first pilot study in GBM, long-term low-dose intramuscular (IM) administration of poly-ICLC demonstrated safety within the HGG participants [66]. Such dosing scheme alleviated toxicities observed earlier in other indications that employed intravenous injection [12]. Most clinical GBM studies retained the IM route, although the three more recent trials administered it subcutaneously (SC). One trial comparing both administration routes could not determine the best choice, as both elicited multi-GAA immunity [70]. In total 80 grade $3 \mathrm{AE}$ and 23 grade $4 \mathrm{AE}$ were possibly due to poly-ICLC, although 16 AE3 and 3 AE4 were possibly observed in non-GBM patients [64]. One AE3 rash could be definitely attributed to poly-ICLC [65]. In the study that controlled for poly-ICLC adjuvant, no increased toxicities were observed apart from mild transient fevers upon vaccination in $2 / 3$ of the patients [74]. The most common AE included injection site reactions and flulike symptoms, but in trials with TMZ, leukopenia was also described. Overall, poly-ICLC was well-tolerated by GBM patients without a clear negative impact on the quality of life.

\section{Immunological effects}

Due to its immunostimulatory effects, poly-ICLC has mostly been employed as a cancer vaccine adjuvant in order to mature DC. Enhanced antigen presentation and $\mathrm{T}$-cell priming then improves the generation of antigenspecific immune responses [12]. In the poly-ICLCadjuvanted GBM vaccination studies, GAA-specific $\mathrm{CD}^{+}$and/or $\mathrm{CD}^{+}{ }^{+} \mathrm{T}$-cell responses were observed in $43 / 57$ patients (75.4\%; range 40.0-100.0\%), of which $69.8 \%$ showed T-cell reactivity against multiple GAA [68-73, 75]. Notably, Migliorini et al. observed that admixing poly(I:C) with the IMA950 peptide vaccine 
drastically enabled the induction of specific T-cell responses compared to concomitant poly-ICLC by augmenting the immunization efficacy (16.7 to 92.3\%) [70]. Nonetheless, other studies employing concomitant administration observed specific $\mathrm{T}$-cell responses at higher rates as well $[68,72,73,75]$. Two studies reported the generation of polyfunctional $\mathrm{T}$ cells, the induction/upregulation of antigen-reactive Tmem and the moderate or high expression of PD-1 [68, 69]. Despite their systemic presence, one trial did not find vaccine-specific TIL in 5/5 samples at relapse after vaccination [70]. On the other hand, another study observed increased GAAspecific $\mathrm{CD}^{+}$TIL, with elevated $\mathrm{PD}-1^{+}$at relapse following vaccination, suggesting prior activation, and only few Treg [69]. Interestingly, immunological responses were absent in patients who were on dexamethasone during the priming phase of the vaccination [69]. This should be taken into account during future trial design, since dexamethasone is frequently prescribed to alleviate cerebral edema in GBM patients. The sole trial with a control arm for poly-ICLC did not report on GAAspecific $\mathrm{T}$-cell responses but instead described a log-fold increase in Th1 cytokine secretion when poly-ICLC was concomitantly administered during boosters [74]. Likewise, other trials reported increased Th1 cytokine secretion or production, which Migliorini et al. proved durable from the first vaccination onwards in the admixed formulation [70, 71]. Only one non-vaccination study reported on immunomonitoring, with few serum cytokine changes, most notably an IFN increase [66]. No studies could relate the observed immunological effects to preliminary clinical response nor endogenous GAA expression $[66,70,75]$. Overall, the lack of immunomonitoring in non-vaccination GBM trials prevents the thorough evaluation of immunological responses in these settings. In contrast, poly-ICLC-adjuvanted vaccination has proven to be immunogenic in GBM patients, which is supported by data of randomized clinical trials in other indications [12].

\section{Clinical effects}

Only three studies were phase II, and notably, none of them considered a vaccination trial [63-65]. The other trials were less qualified to report on clinical effects, although the phase I/II studies already render a glimpse into potential clinical benefits. Overall, the following objective response rates (ORR) were observed in a combined total of 63 attestable GBM patients who received poly-ICLC: five complete responses, seven partial responses, 22 stable diseases and 29 progressive diseases [66, 69-73]. This culminates in a disease control rate (DCR) of 46.9\%. However, since ORR and DCR are subjective to time, we focus on more robust parameters, e.g. overall survival (OS), progression-free survival (PFS) and time- to-progression (TTP). The landmark 2005 phase III EORTC trial on TMZ will serve as a frame of reference (1).

The one study prior to the landmark TMZ trial investigated poly-ICLC as stand-alone or in combination with concurrent chemotherapy. For newly-diagnosed GBM patients, mOS was 11 months with a single weekly injection, but rose to 19 months when 2-3 injections per week were administered [66]. Remarkably, this is longer than the contemporary reference of 14.6 months. Of note, this considered a phase I/II trial and hence, underpowered for conclusive assessment of therapeutic efficacy. Also noteworthy, the few recurrent GBM patients survived for 15 or 19 months, depending on the presence/absence of concurrent chemotherapy [66]. Redefinition of the SOC to include TMZ following the EORTC trial prematurely terminated the exploration of polyICLC concurrent plus adjuvant to radiotherapy in newly-diagnosed GBM patients. OS was similar to the EORTC trial, but the time to progression was shorter, although results were improved compared to radiotherapy alone [63]. As such, it is curious whether poly-ICLC could have made it to phase III and the SOC, if the EORTC trial would not have been. Thereafter, polyICLC during the adjuvant TMZ maintenance phase of the Stupp protocol showed improved OS compared to the landmark TMZ trial, even more so when only the 18-70-year old cohort was considered (mOS 17.2 and 18.3 months, respectively). Consequently, the total group showed a reduced hazard ratio for death (0.46 vs 0.63 ) [65]. Importantly, Rosenfeld et al. acknowledged the presence of confounding factors in their comparison with the EORTC trial, such as the smaller scale of their multi-institutional network, i.e. 6 vs $>80$, the latter for which it is nearly impossible to apply highly similar treatment approaches [65]. Ultimately, with the rise of immunotherapy for brain cancer, the focus with polyICLC shifted toward adjuvanting vaccines.

The vaccination studies look promising, keeping in mind they are underpowered. For instance, the studies reported by Okada et al. and Pollack et al. achieved similar results as the TMZ landmark trial but were performed on recurrent GBM, which has an even worse prognosis [71, 72]. In addition, Pollack reported a mOS of 25.1 months with poly-ICLC-adjuvanted vaccination in newly-diagnosed pediatric GBM patients [73]. In a trial enrolling both newly-diagnosed/recurrent GBM, mOS rose from 17.3 to 22.3 months when poly-ICLC was added [74]. While this hints at the potential for poly-ICLC, the authors emphasized its contribution was unclear since it was only administered with the booster vaccines [74]. These investigators are currently running a follow-up phase II trial (NCT01204684; Table 2). The recent poly-ICLC-adjuvanted multipeptide vaccination studies also reported promising clinical effects on small 
sample sizes, ranging from $16.8-29.0$ months mOS and 7.6-14.2 months mPFS [68-70]. A post-hoc exploration of the poly-ICLC-adjuvanted IMA950 vaccine regarding increased sensitivity to bevacizumab after relapse concluded a negative result, although the authors suggest a concurrent use may unlock potential synergy in this immune/anti-angiogenic combination [67]. This concurrent strategy was investigated in a completed phase II trial (NCT02078648; Table 2). While awaiting the definite report, the disclosed preliminary findings describe major responses and a promising survival curve [76].

In summary, although preliminary findings indicate beneficial responses when combined with the SOC, the future of poly-ICLC in GBM lies within immunotherapy regimens. Nonetheless, despite evidence of immunological activity in poly-ICLC-adjuvanted vaccination studies, additional phase $\geq$ II studies involving more patients are warranted to reliably evaluate the promising preliminary clinical observations. Presumably, combination with other treatments such as ICB is required to adequately potentiate the immunotherapeutic effect.

\section{Ongoing clinical studies}

Table 2 presents the five currently ongoing clinical trials for GBM patients with poly-ICLC as an investigational drug. Notably, all trials consider vaccination studies. Three studies investigate the addition of ICB. Another trial assesses the addition of poly-ICLC-adjuvanted vaccines to tumor-treating fields, the latest approved, though controversial, modality for GBM. The last clinical trial considers a phase II study following the phase I study of Prins et al. discussed above [74].

\section{Discussion}

Safety is the primary concern for any drug. Unlike treatment of hepatocellular and pharyngeal carcinoma cell lines [25, 26], poly(I:C)-induced migration or invasion of GBM cells is not reported. In fact, whereas no protumorigenic effects on GBM cell health have been reported, poly(I:C)-induced cytotoxic outcomes have been described numerously, which is in line with the innate defense mechanism of virus-infected cells against viral spreading [24]. Moreover, in vivo safety and tolerability has been evidenced. Indeed, poly(I:C)-related safety issues from the early days have been dealt with [12], as evidenced by 57 ongoing (of 119 total registered) clinical trials (clinicaltrials.gov). Nonetheless, more definitive data on migration and invasion of GBM cells following poly $(\mathrm{I}: \mathrm{C})$ treatment could provide closure of this lingering issue.

The formulation of poly(I:C) requires more research, given that this determines which receptors are primarily targeted. While TLR-3 and the cytoplasmic receptors share overlapping signaling cascades, their differences can modulate the height or presence/absence of a certain response. In this context, preclinical data suggest that increased targeting of the cytosolic receptors might increase tumorlysis $[28,31,54,55]$. Clinical application of poly(I:C) in GBM has been limited to poly-ICLC (Hiltonol, Oncovir). Recently, a nanoplexed form of poly(I:C) coupled to polyethylenimine (BO-112, Bioncotech Pharmaceuticals), has entered the clinical phase for solid tumors, where it will be combined with antiPD-1 (NCT02828098). Interestingly, BO-112 was found superior to poly(I:C) in preclinical non-GBM tumor models following intratumoral administration [77]. For the purpose of accommodating GBM patients, a comparison between BO-112 and poly-ICLC in GBM is warranted. In addition, novel alternatives are being developed, e.g. a short dsRNA monoclonal antibody (TL532, Tollys) and DNA-capped dsRNA (ARNAX, Hikkaido University). ARNAX performed similarly to poly(I:C) in wild-type and tumor-bearing mice, though with minimal cytokine secretion to enhance its tolerability [78].

Poly(I:C) activates immune cells and it seems that GBM cells respond similarly, secreting pro-inflammatory and lymphocyte-attractive cytokines. Such an immunostimulatory environment is required to render GBM susceptible to immunotherapy. Notably, the pro-inflammatory mesenchymal GBM subtype is particularly immunogenic and more susceptible to immunomanipulation [74, 79]. Moreover, GBM is considered a cold tumor, lacking high numbers of non-exhausted TIL and an adequate antigen presenting machinery [4]. Preclinical data suggest poly(I:C) could aid in overcoming these hurdles, as visualized in Fig. 4. Antigen presentation could be targeted by poly(I:C)-mediated DC activation. Concerning the immunological temperature of GBM, poly(I:C)-mediated Th1 cytokine and chemokine secretion has been clinically observed [70, 71, 74]. Importantly, such Th1 secretome - driven by CXCR3 ligands was preclinically demonstrated as critical for cytotoxic lymphocyte recruitment enabling the efficacy of glioma vaccines as well as ICB in solid tumors [60, 80]. These observations are further supported by the poly(I:C)-mediated conversion of immune-cold to immune-hot lesions in melanoma [81]. In addition, systemic poly(I:C) enables brain trafficking of $\alpha 4$-integrin-deficient lymphocytes [82]. This could also open up avenues for stimulating tumor influx of CAR lymphocyte products. While poly-ICLC did not render GBM immune-hot in the clinical vaccination studies, increased numbers of GAA-specific $\mathrm{T}$ cells were detected [70]. Moreover, an unbiased systems approach in two solid tumor mouse models identified poly(I:C) as one of three critical compounds to convert the TME susceptible to ICB by upregulation signal of transducer and activator of transcription 1 and TLR-3 signaling [83]. Rational combination strategies and modulation of administration/formulation 


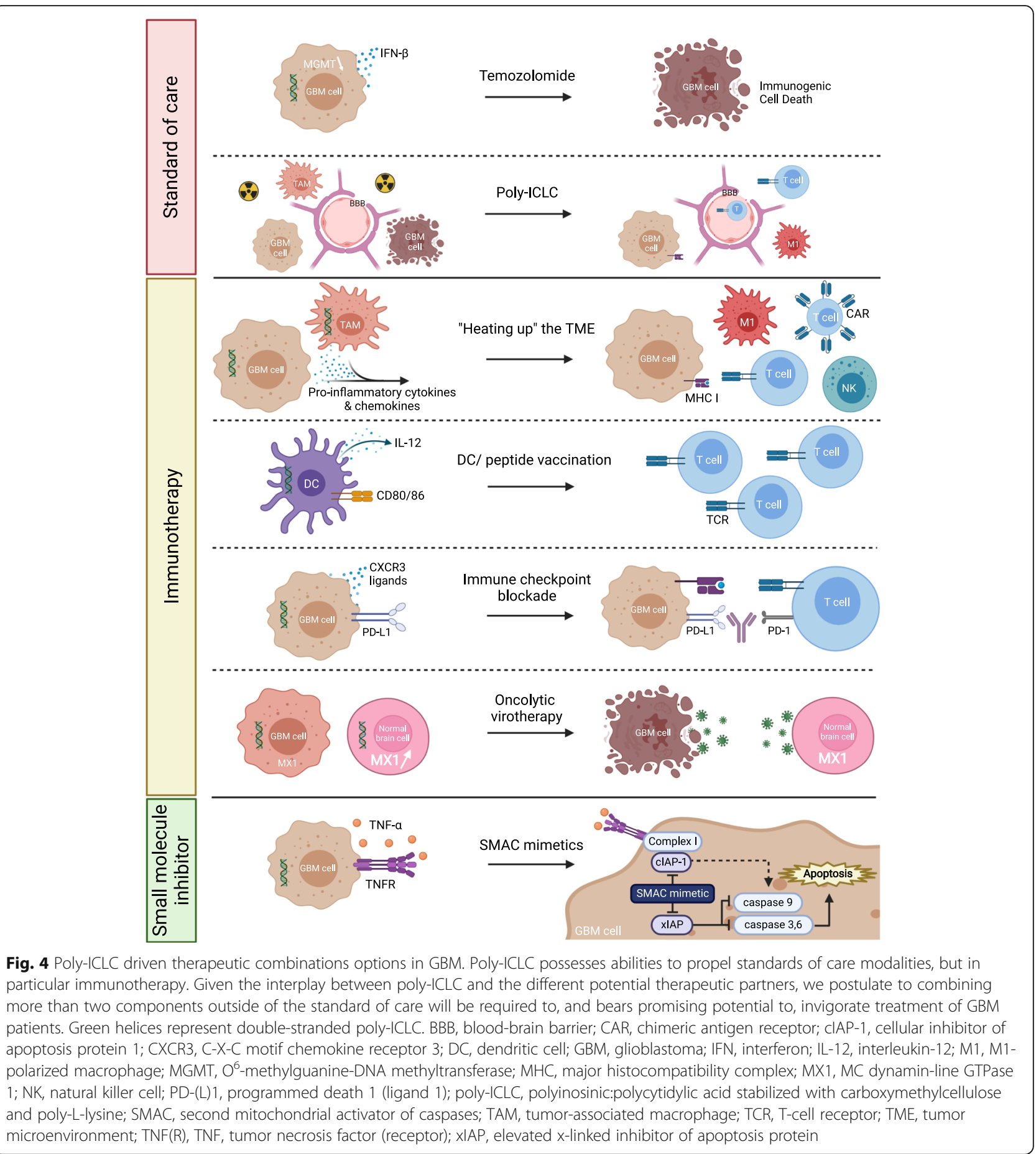

may further close the gap between these two TME immunological phenotypes. An intriguing option to accelerate this phenomenon could be to transiently deliver poly-ICLC intratumorally following surgical resection via injection, lavage or micropumps, although the effect on healthy brain should be cautiously monitored.

Both vaccination and ICB are yet to deliver on their beneficial promises in GBM treatment, thus emphasizing the need for more rational strategies. Pre-/clinical evidence points towards a promising therapeutic triangle between poly(I:C), vaccination and ICB in GBM: (i) poly-ICLC-adjuvanted vaccination is capable of generating GAA-reactive PD- $1^{+} \mathrm{T}$ cells [68-71]; (ii) poly(I:C) is a strong maturation signal for $\mathrm{DC}$ antigen presentation [12]; and (iii) poly(I:C) has preclinically shown to synergize with ICB in GBM, dependent on antigen-presenting 
DC $[30,59]$. Indeed, ICB not only alleviates inhibitory signaling in the TME, but also during DC-mediated Tcell priming in the dLN [84]. The field is evolving towards this triangle, as evidenced by fifteen ongoing trials combining these three therapeutic arms, of which two studies in GBM. Cross-presentation could further be potentiated by the addition of fms-like tyrosine kinase 3 ligand, or Flt3L [85]. In addition, the treatment scheme should be carefully considered. Recently, neo-adjuvant anti-PD-1 treatment was reported to double the mOS compared to the adjuvant setting in a small cohort recurrent GBM patients [86]. While vaccination in a neoadjuvant setting is less feasible, administering poly-ICLC earlier in combination with ICB could render greater development of immunity. This triangle could be further potentiated by induction of ICD, despite limited clinical evidence of ICD in GBM [4]. The novel BO-112 appears to be a strong ICD inducer, contrary to poly(I:C) [77]. This may unlock closed avenues in the treatment strategy.

Smac mimetics lead to tumor cell apoptosis when combined with agents that induce IL- $1 \beta$, IFN- $\beta$, TNF- $\alpha$ and TRAIL [58]. Since poly(I:C) induces such secretion by tumor and stromal cells $[23,30]$, its recent preclinical synergistic pairing with Smac mimetics in GBM holds an intriguing promise that warrants further investigation [58]. Moreover, Smac mimetics also synergize with oncolytic viruses and ICB, a duo which, in combination, also has demonstrated preclinical success [58, 87]. Hence, one could envision a multimodal treatment strategy wherein poly(I:C) (i) guides tumor cell apoptosis, (ii) potentiates anti-tumor immunity, and (iii) confers protection for normal human brain cells [30, 42, 58].

While we have focused on the GBM cells in the in vitro studies, brain tumor-infiltrating microglia and macrophages (BTIM) should not be neglected. This cell population presents an obstinate problem in GBM given their prevalence and GBM-supporting/immunosuppressive phenotype [88]. Indeed, depolarization of protumorigenic BTIM via inhibition of CSF-1R resulted in GBM regression and increased survival [89]. Alternatively, poly(I:C) converted pGBM-derived BTIM towards an oncotoxic, phagocytic and locomostatic profile against pGBM [23], similar to observations in a lung tumor model [90]. In addition, poly(I:C) leads to the secretion of macrophage-derived CXCR3 ligands that have been identified as fundamental for therapeutic efficacy of ICB $[21,22,80]$. Hence, adding poly(I:C) to an immunotherapeutic regimen may also tackle the largest immunosuppressive cell population in the TME of GBM and redirect them to lymphocyte attractors, thus further empowering its potential to enhance the cancerimmunity cycle. Notably, BTIM pre-stimulation with poly $(\mathrm{I}: \mathrm{C})$ was required to overcome GBM-induced suppression [23], which rationalizes the application of poly(I:C) after surgical tumor debulking. Of course, poly(I:C)-induced activation of antigen-presenting cells, particularly DC [13], should not be overlooked and is a crucial part of its mode of action.

Until immunotherapy breaks through as an approved therapeutic option for GBM, the SOC still consists of chemoradiotherapy. Responsiveness to TMZ is dictated by $\mathrm{O}^{6}$-methylguanine-DNA methyltransferase (MGMT) promotor methylation status [91]. IFN- $\beta$ can sensitive GBM cells to TMZ by suppressing MGMT activity [92], although the SOC + IFN- $\beta$ did not lead to a significant survival benefit in the phase II INTEGRA trial [93]. However, a recent murine orthotopic GBM study demonstrated a significant survival prolongation upon nasally administered brain-targeted delivery of poly(I:C) to circumvent the BBB [40]. Here, poly(I:C) produced endogenous IFN- $\beta$ while attenuating MGMT, allowing TMZ to kill the GBM cells in an immunogenic manner [40]. Given that clinical studies with poly-ICLC in GBM have yielded modest results, a key to success may lie in bringing poly(I:C) to the tumor. Indeed, poly(I:C) in mouse models of other tumor types has been very effective when administered intratumorally [77, 81]. The other SOC component, radiotherapy, has been attributed to have immunogenic properties. Combination with poly(I: C) could be beneficial by stimulating the antigenpresenting cells and subsequent $\mathrm{T}$-cell trafficking, facilitated by a radiation-induced increase in BBB permeability, in order to fully engage with radiation-induced ICD [94]. On the other hand, radiotherapy could also have immunosuppressive effects, including induction of M2 macrophages [95], which can be repolarized by poly(I:C) [23]. Intriguingly, despite interesting clinical effects in a phase II trial, poly-ICLC complimentary to the Stupp protocol was not further investigated [65], although its true value would lie in adjuvanting immunotherapy.

Although preclinical evidence regarding poly(I:C) in GBM treatment is very promising, the clinical effect is less pronounced. While immunological activity was observed in the vaccination studies, their statistical power preaches prudence regarding conclusions on clinical benefit. The incidence of GBM, a patient's fitness and the number of ongoing GBM studies are limiting factors in achieving sufficient patient enrollment for large sample sizes. Indeed, GBM remains a rare disease that is more prevalent in elders, whose comorbidities may fit the inclusion criteria less [96], which hampers the estimated accrual of the 522 ongoing GBM clinical trials. Therefore, rational study designs based on solid preclinical foundations are crucial in guiding the most promising strategies towards the clinic. In order to increase the translation of preclinical results, higher-fidelity preclinical models and manipulations are warranted. In vitro 
work on "archaic" 2D-cultured GBM cell lines is being replaced by primary patient-derived tumor cell cultures, (brain-specific) 3D architectures and organoid models [30, 97-102], bringing the in vitro work closer to the reality in the clinic. Whereas GL261 remains the most commonly used animal model for GBM, geneticallyengineered, humanized and immunotherapy-resistant mouse models $[103,104]$ will solidify the informational relevancy. Importantly, a full immune system and a complete display of all GBM hallmarks should be present in these animal models. In addition, adopting stratified models of GBM subtypes in preclinical research might guide patient selection in clinical trials, benefiting both patient and trial. Besides the constitution of in vivo models, the clinical procedures should be taken into account. In humans, GBM treatment is generally initiated by surgical resection. However, this procedure is seldomly carried out in mouse models. The recent neo-adjuvant ICB study has demonstrated the potential significance of the presence/absence of the primary tumor bulk in immunotherapeutic strategies [86], which could partly account for the poor clinical translation. In addition, the subsequent SOC procedures as well as symptomatic relief treatments are perpetually neglected, although they notoriously exert immunosuppressive effects, as recently demonstrated for dexamethasone [4, $69,105]$. Hence, to improve clinical translation, it will be imperative to not only create high-fidelity models, but also to align the preclinical therapeutic manipulations and experimental settings closely to the clinic. In the meantime, we eagerly await the results from the ongoing clinical trials.

\section{Conclusions}

The value of poly $(\mathrm{I}: \mathrm{C})$ derivatives lies in their potential cytotoxic tumor effect and stimulation of anti-tumor immunity with a pivotal role for activating DC. By exerting these functions, it can interact at multiple stages of the cancer-immunity cycle [47]: (i) release antigens via (immunogenic) cytotoxicity, (ii) instigate antigen presentation by DC, (iii) aid T-cell priming by releasing IFN- $\alpha / \beta$ and other cytokines, (iv) stimulate $\mathrm{T}$-cell recruitment via tumor- and macrophage-secreted chemokines, and (v) improve T-cell recognition of tumor cells via increased MHC expression. The accompanying increased PD-L1 expression should be a primary target to be leveraged for combination to further accelerate through this cycle. Hence, poly(I:C) derivatives could serve as central contributors in future immunotherapeutic strategies for GBM - primarily in an adjuvant role - of which multiple rational combinations hold promise. For these reasons, poly(I:C)-derivatives deserve substantial consideration as an adjuvant to boost immunotherapeutic clinical approaches for GBM.

\begin{abstract}
Abbreviations
AE: Adverse events; AP-1: Activator protein 1; BBB: Blood brain barrier; CAR: Chimeric antigen receptor; DC: Dendritic cell; DCR: Disease control rate; dLN: tumor-draining lymph node; GAA: Glioma-associated antigen; GBM: Glioblastoma; HGG: High-grade glioma; ICB: immune checkpoint blockade; ICD: Immunogenic cell death; IFN: Interferon; IKK: Inhibitor of NFKB kinase; IL: Interleukin; IM: Intramuscular; IRF: IFN regulatory factor; ISRE3: IFNstimulated response element 3; MAVS: Mitochondrial antiviral signaling protein; MDA-5: Melanoma differentiation-associated gene 5; MHC: Major histocompatibility complex; (m)OS: (median) overall survival; NFKB: Nuclear factor $\mathrm{k}$-light-chain-enhancer of activated B cells; NK cells: Natural killer cells; ORR: Objective response rate; PD-L1/2: Programmed cell death 1/2 ligand; PEG: Pegylated; PFS: Progression-free survival; pGBM cells: primary human glioblastoma cells; pGSC: primary glioblastoma stem cells; Poly(I:C): Polyinosinic:polycytidylic acid; Poly-ICLC: Poly(I:C) stabilized with carboxymethylcellulose and poly-L-lysine; RIG-I: Retinoic acid-inducible gene I; RIP-1: Receptor-interacting serine/threonine-protein kinase 1;

SC: Subcutaneous; SOC: Standard of care; TAK1: TGF- $\beta$ activated kinase 1;

TAM: Tumor-associated macrophage; TBK1: TRAF family member associated NFKB activator binding kinase 1; TGF- $\beta$ : Transforming growth factor $\beta$; TICA M1: TLR adaptor molecule 1; TIL: Tumor-infiltrating lymphocytes; TLR-3: Tolllike receptor 3; TNF: Tumor necrosis factor; TME: Tumor microenvironment; Tmem: Memory T cells; TRAF: TNF receptor associated factor;

Treg: Regulatory T cells; TTP: Time-to-progression; TMZ: Temozolomide
\end{abstract}

\section{Acknowledgments}

The authors would like to thank Dr. Abraham Lin for copy editing the manuscript. Figures were created with BioRender.com.

\section{Authors' contributions}

J.D.W. conceived the paper and wrote the manuscript. J.D.W., T.V. and S.V.D.H. designed the figures. T.V., S.V.D.H., Z.N.B., M.P., F.L., A.W. and E.L.J.M.S. substantively and critically revised the manuscript. All authors approved the final and submitted version of the manuscript.

\section{Funding}

This work was supported by research grants of the Research Foundation Flanders (FWO), the Flemish cancer society "Kom op tegen Kanker" (Stand Up to Cancer), the Multidisciplinary Oncological Center Antwerp (MOCA) from the Antwerp University Hospital (UZA) and the University of Antwerp (BOF). The authors would also like to thank Mr. Willy Floren and the Vereycken family for financial support.

Availability of data and materials

Not applicable.

\section{Declarations}

Ethics approval and consent to participate

No applicable.

Consent for publication

No applicable.

\section{Competing interests}

The authors declare that they have no competing interests.

\section{Author details}

${ }^{1}$ Center for Oncological Research (CORE), Integrated Personalized \& Precision Oncology Network (IPPON), University of Antwerp, Universiteitsplein 1, B-2610 Antwerp, Belgium. '2Laboratory of Experimental Hematology, University of Antwerp, Universiteitsplein 1, B-2610 Antwerp, Belgium. ${ }^{3}$ Department of Hematology, Antwerp University Hospital, Wilrijkstraat 10, B-2650 Edegem, Belgium. ${ }^{4}$ Center for Cell Therapy and Regenerative Medicine, Antwerp University Hospital, Wilrijkstraat 10, B-2650 Edegem, Belgium. ${ }^{5}$ Multidisciplinary Oncological Center Antwerp, Antwerp University Hospital, Wilrijkstraat 10, B-2650 Edegem, Belgium. 
Received: 18 January 2021 Accepted: 14 June 2021

Published online: 25 June 2021

\section{References}

1. Stupp R, Mason WP, van den Bent MJ, Weller M, Fisher B, Taphoorn MJ, et al. Radiotherapy plus concomitant and adjuvant temozolomide for glioblastoma. N Engl J Med. 2005;352(10):987-96. https://doi.org/10.1056/ NEJMoa043330.

2. Ostrom QT, Patil N, Cioffi G, Waite K, Kruchko C, Barnholtz-Sloan JS. CBTRUS Statistical Report: Primary Brain and Other Central Nervous System Tumors Diagnosed in the United States in 2013-2017. Neuro Oncol. 2020;22(12 Suppl 2):iv1-iv96.

3. Gramatzki D, Roth P, Rushing EJ, Weller J, Andratschke N, Hofer S, et al. Bevacizumab may improve quality of life, but not overall survival in glioblastoma: an epidemiological study. Ann Oncol. 2018;29(6):1431-6. https://doi.org/10.1093/annonc/mdy106.

4. Lim M, Xia Y, Bettegowda C, Weller M. Current state of immunotherapy for glioblastoma. Nat Rev Clin Oncol. 2018;15(7):422-42. https://doi.org/10.1038/ s41571-018-0003-5

5. Chamberlin MJ, Patterson DL. Physical and chemical characterization of the ordered complexes formed between Polyinosinic acid, Polycytidylic acid and their Deoxyribo-analogues. J Mol Biol. 1965;12(2):410-28. https://doi. org/10.1016/S0022-2836(65)80264-9

6. Yu M, Levine SJ. Toll-like receptor, RIG-l-like receptors and the NLRP3 inflammasome: key modulators of innate immune responses to doublestranded RNA viruses. Cytokine Growth Factor Rev. 2011;22(2):63-72. https:// doi.org/10.1016/j.cytogfr.2011.02.001.

7. Desmet CJ, Ishii KJ. Nucleic acid sensing at the interface between innate and adaptive immunity in vaccination. Nat Rev Immunol. 2012;12(7):479-91. https://doi.org/10.1038/nri3247.

8. Kawai T, Akira S. Toll-like receptor and RIG-l-like receptor signaling. Ann N Y Acad Sci. 2008;1143(1):1-20. https://doi.org/10.1196/annals.1443.020.

9. Sultan H, Wu J, Kumai T, Salazar AM, Celis E. Role of MDA5 and interferon-I in dendritic cells for T cell expansion by anti-tumor peptide vaccines in mice. Cancer Immunol Immunother. 2018;67(7):1091-103. https://doi.org/1 0.1007/s00262-018-2164-6.

10. Kato H, Takeuchi O, Mikamo-Satoh E, Hirai R, Kawai T, Matsushita K, et al, Length-dependent recognition of double-stranded ribonucleic acids by retinoic acid-inducible gene-I and melanoma differentiation-associated gene 5. J Exp Med. 2008;205(7):1601-10. https://doi.org/10.1084/jem.2 0080091.

11. Zou J, Kawai T, Tsuchida T, Kozaki T, Tanaka H, Shin KS, et al. Poly IC triggers a cathepsin D- and IPS-1-dependent pathway to enhance cytokine production and mediate dendritic cell necroptosis. Immunity. 2013;38(4): 717-28. https://doi.org/10.1016/j.immuni.2012.12.007

12. Ammi R, De Waele J, Willemen $Y$, Van Brussel I, Schrijvers DM, Lion E, et al. Poly $(\mathrm{l}: \mathrm{C})$ as cancer vaccine adjuvant: knocking on the door of medical breakthroughs. Pharmacol Ther. 2015;146:120-31. https://doi.org/10.1016/j. pharmthera.2014.09.010.

13. Fucikova J, Rozkova D, Ulcova H, Budinsky V, Sochorova K, Pokorna K, et al. Poly I: C-activated dendritic cells that were generated in CellGro for use in cancer immunotherapy trials. J Transl Med. 2011;9(1):223. https://doi.org/1 0.1186/1479-5876-9-223.

14. Gutcher I, Becher B. APC-derived cytokines and T cell polarization in autoimmune inflammation. J Clin Invest. 2007;117(5):1119-27. https://doi. org/10.1172/JCl31720.

15. Moller I, Michel K, Frech N, Burger M, Pfeifer D, Frommolt $P$, et al. Dendritic cell maturation with poly(l:C)-based versus PGE2-based cytokine combinations results in differential functional characteristics relevant to clinical application. J Immunother (Hagerstown, Md : 1997). 2008;31(5): 506-19.

16. Cho HI, Celis E. Optimized peptide vaccines eliciting extensive CD8 T-cell responses with therapeutic antitumor effects. Cancer Res. 2009:69(23):90129. https://doi.org/10.1158/0008-5472.CAN-09-2019.

17. Longhi MP, Trumpfheller C, Idoyaga J, Caskey M, Matos I, Kluger C, et al. Dendritic cells require a systemic type I interferon response to mature and induce CD4+ Th1 immunity with poly IC as adjuvant. J Exp Med. 2009; 206(7):1589-602. https://doi.org/10.1084/jem.20090247.

18. Gerosa F, Gobbi A, Zorzi P, Burg S, Briere F, Carra G, et al. The reciprocal interaction of NK cells with plasmacytoid or myeloid dendritic cells profoundly affects innate resistance functions. J Immunol (Baltimore, Md : 1950). 2005:174(2):727-34.

19. Akazawa T, Ebihara T, Okuno M, Okuda $Y$, Shingai M, Tsujimura K, et al. Antitumor NK activation induced by the toll-like receptor 3-TICAM-1 (TRIF) pathway in myeloid dendritic cells. Proc Natl Acad Sci U S A. 2007;104(1): 252-7. https://doi.org/10.1073/pnas.0605978104

20. Pisegna S, Pirozzi G, Piccoli M, Frati L, Santoni A, Palmieri G. p38 MAPK activation controls the TLR3-mediated up-regulation of cytotoxicity and cytokine production in human NK cells. Blood. 2004;104(13):4157-64. https://doi.org/10.1182/blood-2004-05-1860.

21. Maeda A, Digifico E, Andon FT, Mantovani A, Allavena P. Poly(l:C) stimulation is superior than Imiquimod to induce the antitumoral functional profile of tumor-conditioned macrophages. Eur J Immunol. 2019;49(5):80111. https://doi.org/10.1002/eji.201847888.

22. Rose M, Duhamel M, Aboulouard S, Kobeissy F, Tierny D, Fournier I, et al. Therapeutic anti-glioma effect of the combined action of PCSK inhibitor with the anti-tumoral factors secreted by poly (I:C)-stimulated macrophages. Cancer Gene Ther. 2021. https://doi.org/10.1038/s41417-020-00286-1.

23. Kees T, Lohr J, Noack J, Mora R, Gdynia G, Todt G, et al. Microglia isolated from patients with glioma gain antitumor activities on poly (I:C) stimulation. Neuro Oncol. 2012;14(1):64-78. https://doi.org/10.1093/neuonc/nor182.

24. Chen YB, Seo SY, Kirsch DG, Sheu TT, Cheng WC, Hardwick JM. Alternate functions of viral regulators of cell death. Cell Death Differ. 2006;13(8):131824. https://doi.org/10.1038/sj.cdd.4401964.

25. Feng Y, Chen Y, Meng Y, Cao Q, Liu Q, Ling C, et al. Bufalin suppresses migration and invasion of hepatocellular carcinoma cells elicited by poly (I: C) therapy. Oncoimmunology. 2018;7(5):e1426434. https://doi.org/10.1 080/2162402X.2018.1426434.

26. Matijevic Glavan T, Cipak Gasparovic A, Verillaud B, Busson P, Pavelic J. Tolllike receptor 3 stimulation triggers metabolic reprogramming in pharyngeal cancer cell line through Myc, MAPK, and HIF. Mol Carcinog. 2017:56(4): 1214-26. https://doi.org/10.1002/mc.22584.

27. Moher D, Liberati A, Tetzlaff J, Altman DG, Group P. Preferred reporting items for systematic reviews and meta-analyses: the PRISMA statement. BMJ. 2009;339:b2535. https://doi.org/10.1136/bmj.b2535.

28. Bucur N, Mizuno M, Wakabayashi T, Yoshida J. Growth inhibition of experimental glioma by human interferon-beta superinduced by cationic liposomes entrapping polyinosilic:polycytidilic acid. Neurol Med Chir. 1998; 38(8):469-73; discussion 73-4. https://doi.org/10.2176/nmc.38.469.

29. Carpenter S, Wochal P, Dunne A, O'Neill LA. Toll-like receptor 3 (TLR3) signaling requires TLR4 interactor with leucine-rich REPeats (TRIL). J Biol Chem. 2011;286(44):38795-804. https://doi.org/10.1074/jbc.M111.255893.

30. De Waele J, Marcq E, Van Audenaerde JR, Van Loenhout J, Deben C, Zwaenepoel K, et al. Poly(l:C) primes primary human glioblastoma cells for an immune response invigorated by PD-L1 blockade. Oncoimmunology. 2018;7(3):e1407899. https://doi.org/10.1080/2162402X.2017.1407899.

31. Glas M, Coch C, Trageser D, Dassler J, Simon M, Koch P, et al. Targeting the cytosolic innate immune receptors RIG-I and MDA5 effectively counteracts cancer cell heterogeneity in glioblastoma. Stem Cells. 2013;31(6):1064-74. https://doi.org/10.1002/stem.1350.

32. Imaizumi T, Numata A, Yano C, Yoshida H, Meng P, Hayakari R, et al. ISG54 and ISG56 are induced by TLR3 signaling in U373MG human astrocytoma cells: possible involvement in CXCL10 expression. Neurosci Res. 2014;84:3442. https://doi.org/10.1016/j.neures.2014.03.001.

33. Imaizumi $T$, Sakashita $N$, Mushiga $Y$, Yoshida $H$, Hayakari $R$, Xing $F$, et al. Desferrioxamine, an iron chelator, inhibits CXCL10 expression induced by polyinosinic-polycytidylic acid in U373MG human astrocytoma cells. Neurosci Res. 2015;94:10-6. https://doi.org/10.1016/j.neures.2015.01.001.

34. Imaizumi $T$, Yoshida $H$, Hayakari $R$, Xing F, Wang $L$, Matsumiya $T$, et al. Interferon-stimulated gene (ISG) 60, as well as ISG56 and ISG54, positively regulates TLR3/IFN-beta/STAT1 axis in U373MG human astrocytoma cells. Neurosci Res. 2016;105:35-41. https://doi.org/10.1016/j.neures.2015.09.002.

35. Osawa H, Mizuno M, Hatano M, Nakahara N, Tsuno T, Kuno T, et al. Susceptibility to exogenously added interferon-beta protein depends on intracellular interferon-beta mRNA level in human glioma cells. Cytokine. 2005:32(5):240-5. https://doi.org/10.1016/j.cyto.2005.10.003.

36. Park KC, Shimizu K, Hayakawa T. Interferon yield and MHC antigen expression of human medulloblastoma cells and its suppression during dibutyryl cyclic AMP-induced differentiation: do medulloblastoma cells derive from bipotent neuronal and glial progenitors? Cell Mol Neurobiol. 1998;18(5):497-507. https://doi.org/10.1023/A:1026327309345. 
37. Shirai K, Shimada T, Yoshida H, Hayakari R, Matsumiya T, Tanji K, et al. Interferon (IFN)-induced protein 35 (IFI35) negatively regulates IFN-betaphosphorylated STAT1-RIG-I-CXCL10/CCL5 axis in U373MG astrocytoma cells treated with polyinosinic-polycytidylic acid. Brain Res. 2017;1658:60-7.

38. Yoshida H, Imaizumi T, Matsumiya T, Seya K, Kawaguchi S, Tanaka H. Gnetin C suppresses double-stranded RNA-induced C-C motif chemokine ligand 2 (CCL2) and CCL5 production by inhibiting Toll-like receptor 3 signaling pathway. Biomed Res (Tokyo, Japan). 2018;39(5):231-40.

39. Zhu X, Nishimura F, Sasaki K, Fujita M, Dusak JE, Eguchi J, et al. Toll like receptor-3 ligand poly-ICLC promotes the efficacy of peripheral vaccinations with tumor antigen-derived peptide epitopes in murine CNS tumor models. J Transl Med. 2007;5(1):10. https://doi.org/10.1186/1479-5876-5-10.

40. Yin P, Li H, Ke C, Cao G, Xin X, Hu J, et al. Intranasal delivery of immunotherapeutic Nanoformulations for treatment of glioma through in situ activation of immune response. Int J Nanomedicine. 2020;15:1499-515. https://doi.org/10.2147/JN.S240551.

41. Chacko MS, Ma X, Adamo ML. Double-stranded ribonucleic acid decreases c6 rat glioma cell proliferation in part by activating protein kinase $R$ and decreasing insulin-like growth factor I levels. Endocrinology. 2002;143(6): 2144-54. https://doi.org/10.1210/endo.143.6.8835.

42. Wollmann G, Robek MD, van den Pol AN. Variable deficiencies in the interferon response enhance susceptibility to vesicular stomatitis virus oncolytic actions in glioblastoma cells but not in normal human glial cells. $J$ Virol. 2007;81(3):1479-91. https://doi.org/10.1128/JVI.01861-06.

43. Ghali M, Schneider-Schaulies J. Receptor (CD46)- and replication-mediated interleukin-6 induction by measles virus in human astrocytoma cells. J Neurovirol. 1998:4(5):521-30. https://doi.org/10.3109/13550289809113496.

44. Grauer OM, Molling JW, Bennink E, Toonen LW, Sutmuller RP, Nierkens S, et al. TLR ligands in the local treatment of established intracerebral murine gliomas. J Immunol (Baltimore, Md : 1950). 2008;181(10):6720-9.

45. Lee K, Kim SJ, Kim D, Jo SH, Joong Lee S, Choi SY. Prostaglandin modulates TLR3-induced cytokine expression in human astroglioma cells. Brain Res. 2014;1589:54-60. https://doi.org/10.1016/j.brainres.2014.06.036.

46. Tarassishin L, Casper D, Lee SC. Aberrant expression of interleukin-1 beta and inflammasome activation in human malignant gliomas. PLoS One. 2014;9(7): e103432. https://doi.org/10.1371/journal.pone.0103432.

47. Chen DS, Mellman I. Oncology meets immunology: the cancer-immunity cycle. Immunity. 2013;39(1):1-10. https://doi.org/10.1016/j.immuni.2013.07. 012.

48. Dhib-Jalbut SS, Xia Q, Drew PD, Swoveland PT. Differential up-regulation of HLA class I molecules on neuronal and glial cell lines by virus infection correlates with differential induction of IFN-beta. J Immunol (Baltimore, Md : 1950). 1995;155(4):2096-108.

49. He Y, Tian Z. NK cell education via nonclassical MHC and non-MHC ligands. Cell Mol Immunol. 2017;14(4):321-30. https://doi.org/10.1038/cmi.2016.26.

50. Ribas A, Wolchok JD. Cancer immunotherapy using checkpoint blockade. Science. 2018;359(6382):1350-5. https://doi.org/10.1126/science.aar4060.

51. Geletneky K, Hajda J, Angelova AL, Leuchs B, Capper D, Bartsch AJ, et al. Oncolytic $\mathrm{H}-1$ parvovirus shows safety and signs of immunogenic activity in a first phase I/lla glioblastoma trial. Mol Ther. 2017;25(12):2620-34. https:// doi.org/10.1016/j.ymthe.2017.08.016.

52. Alain $T$, Kim TS, Lun $X$, Liacini A, Schiff LA, Senger DL, et al. Proteolytic disassembly is a critical determinant for reovirus oncolysis. Mol Ther. 2007: 15(8):1512-21. https://doi.org/10.1038/sj.mt.6300207.

53. Dick RS, Hubbell HR. Sensitivities of human glioma cell lines to interferons and double-stranded RNAs individually and in synergistic combinations. J Neuro-Oncol. 1987;5(4):331-8. https://doi.org/10.1007/BF00148390.

54. Schaffert D, Kiss M, Rodl W, Shir A, Levitzki A, Ogris M, et al. Poly(l:C)mediated tumor growth suppression in EGF-receptor overexpressing tumors using EGF-polyethylene glycol-linear polyethylenimine as carrier. Pharm Res. 2011;28(4):731-41. https://doi.org/10.1007/s11095-010-0225-4.

55. Shir A, Ogris M, Wagner E, Levitzki A. EGF receptor-targeted synthetic double-stranded RNA eliminates glioblastoma, breast cancer, and adenocarcinoma tumors in mice. PLoS Med. 2006;3(1):e6. https://doi.org/1 0.1371/journal.pmed.0030006.

56. Chacko MS, Adamo ML. Double-stranded ribonucleic acid decreases C6 rat glioma cell numbers: effects on insulin-like growth factor I gene expression and action. Endocrinology. 2000;141(10):3546-55. https://doi.org/10.1210/ endo.141.10.7729.

57. Chacko MS, Adamo ML. Double-stranded RNA decreases IGF-I gene expression in a protein kinase R-dependent, but type I interferon- independent, mechanism in C6 rat glioma cells. Endocrinology. 2002;143(2): 525-34. https://doi.org/10.1210/endo.143.2.8628.

58. Beug ST, Beauregard CE, Healy C, Sanda T, St-Jean M, Chabot J, et al. Smac mimetics synergize with immune checkpoint inhibitors to promote tumour immunity against glioblastoma. Nat Commun. 2017;8(1). https://doi.org/10.1 038/ncomms 14278

59. Garzon-Muvdi T, Theodros D, Luksik AS, Maxwell R, Kim E, Jackson CM, et al. Dendritic cell activation enhances anti-PD-1 mediated immunotherapy against glioblastoma. Oncotarget. 2018;9(29):20681-97. https://doi.org/10.1 8632/oncotarget.25061.

60. Zhu X, Fallert-Junecko BA, Fujita M, Ueda R, Kohanbash G, Kastenhuber ER, et al. Poly-ICLC promotes the infiltration of effector T cells into intracranial gliomas via induction of CXCL10 in IFN-alpha and IFN-gamma dependent manners. Cancer Immunol Immunother. 2010;59(9):1401-9. https://doi.org/1 0.1007/s00262-010-0876-3.

61. Zhu X, Fujita M, Snyder LA, Okada H. Systemic delivery of neutralizing antibody targeting CCL2 for glioma therapy. J Neuro-Oncol. 2011;104(1):8392. https://doi.org/10.1007/s11060-010-0473-5.

62. Ohlfest JR, Andersen BM, Litterman AJ, Xia J, Pennell CA, Swier LE, et al. Vaccine injection site matters: qualitative and quantitative defects in CD8 T cells primed as a function of proximity to the tumor in a murine glioma model. Journal of immunology (Baltimore, Md : 1950). 2013;190(2):613-20.

63. Butowski N, Chang SM, Junck L, DeAngelis LM, Abrey L, Fink K, et al. A phase II clinical trial of poly-ICLC with radiation for adult patients with newly diagnosed supratentorial glioblastoma: a north American brain tumor consortium (NABTC01-05). J Neuro-Oncol. 2009;91(2):175-82. https://doi. org/10.1007/s11060-008-9693-3.

64. Hartman LL, Crawford JR, Makale MT, Milburn M, Joshi S, Salazar AM, et al. Pediatric phase II trials of poly-ICLC in the management of newly diagnosed and recurrent brain tumors. J Pediatr Hematol Oncol. 2014;36(6):451-7. https://doi.org/10.1097/MPH.0000000000000047.

65. Rosenfeld MR, Chamberlain MC, Grossman SA, Peereboom DM, Lesser GJ, Batchelor TT, et al. A multi-institution phase II study of poly-ICLC and radiotherapy with concurrent and adjuvant temozolomide in adults with newly diagnosed glioblastoma. Neuro-oncology. 2010;12(10):1071-7. https:// doi.org/10.1093/neuonc/nog071.

66. Salazar AM, Levy HB, Ondra S, Kende M, Scherokman B, Brown D, et al. Long-term treatment of malignant gliomas with intramuscularly administered polyinosinic-polycytidylic acid stabilized with polylysine and carboxymethylcellulose: an open pilot study. Neurosurgery. 1996;38(6):1096103; discussion 103-4. https://doi.org/10.1227/00006123-199606000-00006.

67. Boydell E, Marinari E, Migliorini D, Dietrich PY, Patrikidou A, Dutoit V. Exploratory Study of the Effect of IMA950/Poly-ICLC Vaccination on Response to Bevacizumab in Relapsing High-Grade Glioma Patients. Cancers. 2019;11(4):464. https://doi.org/10.3390/cancers11040464.

68. Hilf N, Kuttruff-Coqui S, Frenzel K, Bukur V, Stevanovic S, Gouttefangeas C, et al. Actively personalized vaccination trial for newly diagnosed glioblastoma. Nature. 2019;565(7738):240-5. https://doi.org/10.1038/s41586018-0810-y.

69. Keskin DB, Anandappa AJ, Sun J, Tirosh I, Mathewson ND, Li S, et al. Neoantigen vaccine generates intratumoral $\mathrm{T}$ cell responses in phase $\mathrm{lb}$ glioblastoma trial. Nature. 2019;565(7738):234-9. https://doi.org/10.1038/s41 586-018-0792-9.

70. Migliorini D, Dutoit V, Allard M, Hallez NG, Marinari E, Widmer V, et al. Phase I/II trial testing safety and immunogenicity of the multipeptide IMA950/ poly-ICLC vaccine in newly diagnosed adult malignant astrocytoma patients. Neuro Oncol. 2019;21 (7):923-33. https://doi.org/10.1093/neuonc/ noz040.

71. Okada H, Kalinski P, Ueda R, Hoji A, Kohanbash G, Donegan TE, et al. Induction of CD8+ T-cell responses against novel glioma-associated antigen peptides and clinical activity by vaccinations with \{alpha\}-type 1 polarized dendritic cells and polyinosinic-polycytidylic acid stabilized by lysine and carboxymethylcellulose in patients with recurrent malignant glioma. J Clin Oncol. 2011;29(3):330-6. https://doi.org/10.1200/JCO.2010.30.7744.

72. Pollack IF, Jakacki RI, Butterfield LH, Hamilton RL, Panigrahy A, Normolle DP, et al. Antigen-specific immunoreactivity and clinical outcome following vaccination with glioma-associated antigen peptides in children with recurrent high-grade gliomas: results of a pilot study. J Neuro-Oncol. 2016; 130(3):517-27. https://doi.org/10.1007/s1 1060-016-2245-3.

73. Pollack IF, Jakacki RI, Butterfield LH, Hamilton RL, Panigrahy A, Potter DM, et al. Antigen-specific immune responses and clinical outcome after 
vaccination with glioma-associated antigen peptides and polyinosinicpolycytidylic acid stabilized by lysine and carboxymethylcellulose in children with newly diagnosed malignant brainstem and nonbrainstem gliomas. J Clin Oncol. 2014;32(19):2050-8. https://doi.org/10.1200/JCO.2013.54.0526.

74. Prins RM, Soto H, Konkankit V, Odesa SK, Eskin A, Yong WH, et al. Gene expression profile correlates with T-cell infiltration and relative survival in glioblastoma patients vaccinated with dendritic cell immunotherapy. Clin Cancer Res. 2011;17(6):1603-15. https://doi.org/10.1158/1078-0432.CCR-10-2 563.

75. Wang QT, Nie Y, Sun SN, Lin T, Han RJ, Jiang J, et al. Tumor-associated antigen-based personalized dendritic cell vaccine in solid tumor patients. Cancer Immunol Immunother. 2020;69(7):1375-87. https://doi.org/10.1007/ s00262-020-02496-w.

76. Peereboom D, Nabors LB, Kumthekar P, Badruddoja M, Fink K, Lieberman F, et al. Results of phase 2 trial of SL-701, a novel immunotherapy targeting IL13Ra2, EphA2, and survivin, in adults with second-line recurrent glioblastoma (GBM). Ann Oncol. 2018;29(suppl_8):viii122-viii3.

77. Aznar MA, Planelles L, Perez-Olivares M, Molina C, Garasa S, Etxeberria I, et al. Immunotherapeutic effects of intratumoral nanoplexed poly I:C. J Immunother Cancer. 2019;7(1):116. https://doi.org/10.1186/s40425-0190568-2.

78. Takeda Y, Kataoka K, Yamagishi J, Ogawa S, Seya T, Matsumoto M. A TLR3specific adjuvant relieves innate resistance to PD-L1 blockade without cytokine toxicity in tumor vaccine immunotherapy. Cell Rep. 2017;19(9): 1874-87. https://doi.org/10.1016/j.celrep.2017.05.015.

79. Doucette T, Rao G, Rao A, Shen L, Aldape K, Wei J, et al. Immune heterogeneity of glioblastoma subtypes: extrapolation from the cancer genome atlas. Cancer Immunol Res. 2013;1(2):112-22. https://doi.org/10.11 58/2326-6066.CIR-13-0028.

80. House IG, Savas P, Lai J, Chen AXY, Oliver AJ, Teo ZL, et al. Macrophagederived CXCL9 and CXCL10 are required for antitumor immune responses following immune checkpoint blockade. Clin Cancer Res. 2020;26(2):487504. https://doi.org/10.1158/1078-0432.CCR-19-1868.

81. Bald T, Landsberg J, Lopez-Ramos D, Renn M, Glodde N, Jansen P, et al. Immune cell-poor melanomas benefit from PD-1 blockade after targeted type I IFN activation. Cancer Discov. 2014;4(6):674-87. https://doi.org/10.11 58/2159-8290.CD-13-0458.

82. Hussain RZ, Cravens PC, Doelger R, Dentel B, Herndon E, Loof N, et al. TLR3 agonism re-establishes CNS immune competence during alpha4-integrin deficiency. Ann Clin Transl Neurol. 2018;5(12):1543-61. https://doi.org/10.1 002/acn3.664

83. Zemek RM, De Jong E, Chin WL, Schuster IS, Fear VS, Casey TH, et al. Sensitization to immune checkpoint blockade through activation of a STAT1/NK axis in the tumor microenvironment. Sci Transl Med. 2019;11(501): eaav7816. https://doi.org/10.1126/scitrans/med.aav7816.

84. Curiel TJ, Wei S, Dong H, Alvarez X, Cheng P, Mottram P, et al. Blockade of B7-H1 improves myeloid dendritic cell-mediated antitumor immunity. Nat Med. 2003;9(5):562-7. https://doi.org/10.1038/nm863.

85. Lee YS, O'Brien LJ, Walpole CM, Pearson FE, Leal-Rojas IM, Masterman KA, et al. Human CD141(+) dendritic cells (CDC1) are impaired in patients with advanced melanoma but can be targeted to enhance anti-PD-1 in a humanized mouse model. J Immunother Cancer. 2021;9(3):e001963. https://doi.org/10.1136/jitc-2020-001963.

86. Cloughesy TF, Mochizuki AY, Orpilla JR, Hugo W, Lee AH, Davidson TB, et al. Neoadjuvant anti-PD-1 immunotherapy promotes a survival benefit with intratumoral and systemic immune responses in recurrent glioblastoma. Nat Med. 2019;25(3):477-86. https://doi.org/10.1038/s41591-018-0337-7.

87. Cockle JV, Rajani K, Zaidi S, Kottke T, Thompson J, Diaz RM, et al. Combination viroimmunotherapy with checkpoint inhibition to treat glioma, based on location-specific tumor profiling. Neuro-oncology. 2016; 18(4):518-27. https://doi.org/10.1093/neuonc/nov173.

88. Graeber MB, Scheithauer BW, Kreutzberg GW. Microglia in brain tumors. Glia. 2002;40(2):252-9. https://doi.org/10.1002/glia.10147.

89. Pyonteck SM, Akkari L, Schuhmacher AJ, Bowman RL, Sevenich L, Quail DF, et al. CSF-1R inhibition alters macrophage polarization and blocks glioma progression. Nat Med. 2013;19(10):1264-72. https://doi.org/10.1038/nm.3337.

90. Shime H, Matsumoto M, Oshiumi H, Tanaka S, Nakane A, Iwakura Y, et al. Toll-like receptor 3 signaling converts tumor-supporting myeloid cells to tumoricidal effectors. Proc Natl Acad Sci U S A. 2012;109(6):2066-71. https:// doi.org/10.1073/pnas.1113099109.
91. Hegi ME, Diserens AC, Gorlia T, Hamou MF, de Tribolet N, Weller M, et al. MGMT gene silencing and benefit from temozolomide in glioblastoma. N Engl J Med. 2005;352(10):997-1003. https://doi.org/10.1056/NEJMoa043331.

92. Natsume A, Wakabayashi T, Ishii D, Maruta H, Fujii M, Shimato S, et al. A combination of IFN-beta and temozolomide in human glioma xenograft models: implication of p53-mediated MGMT downregulation. Cancer Chemother Pharmacol. 2008;61(4):653-9. https://doi.org/10.1007/s00280007-0520-x

93. Wakabayashi T, Natsume A, Mizusawa J, Katayama H, Fukuda H, Sumi M, et al. JCOG0911 INTEGRA study: a randomized screening phase II trial of interferonbeta plus temozolomide in comparison with temozolomide alone for newly diagnosed glioblastoma. J Neuro-Oncol. 2018;138(3):627-36. https://doi.org/10.1007/s11060-018-2831-7.

94. Brown NF, Carter TJ, Ottaviani D, Mulholland P. Harnessing the immune system in glioblastoma. Br J Cancer. 2018;119(10):1171-81. https://doi.org/1 0.1038/s41416-018-0258-8.

95. Chiang CS, Fu SY, Wang SC, Yu CF, Chen FH, Lin CM, et al. Irradiation promotes an $\mathrm{m} 2$ macrophage phenotype in tumor hypoxia. Front Oncol. 2012:2:89.

96. Ostrom QT, Gittleman H, Truitt G, Boscia A, Kruchko C, Barnholtz-Sloan JS. CBTRUS Statistical Report: Primary Brain and Other Central Nervous System Tumors Diagnosed in the United States in 2011-2015. Neuro Oncol. 2018. 20(suppl_4):iv1-iv86.

97. De Waele J, Reekmans K, Daans J, Goossens H, Berneman Z, Ponsaerts P. 3D culture of murine neural stem cells on decellularized mouse brain sections. Biomaterials. 2015;41:122-31. https://doi.org/10.1016/j.biomaterials.2014.11. 025.

98. Akins EA, Aghi MK, Kumar S. Incorporating Tumor-Associated Macrophages into Engineered Models of Glioma. iScience. 2020;23(12):101770.

99. Hubert CG, Rivera M, Spangler LC, Wu Q, Mack SC, Prager BC, et al. A threedimensional organoid culture system derived from human glioblastomas recapitulates the hypoxic gradients and Cancer stem cell heterogeneity of tumors found in vivo. Cancer Res. 2016;76(8):2465-77. https://doi.org/10.11 58/0008-5472.CAN-15-2402.

100. Jacob F, Salinas RD, Zhang DY, Nguyen PTT, Schnoll JG, Wong SZH, et al. A patient-derived glioblastoma organoid model and biobank recapitulates inter- and intra-tumoral heterogeneity. Cell. 2020;180(1):188-204 e22. https://doi.org/10.1016/j.cell.2019.11.036.

101. Linkous A, Balamatsias D, Snuderl M, Edwards L, Miyaguchi K, Milner T, et al. Modeling patient-derived glioblastoma with cerebral organoids. Cell Rep. 2019;26(12):3203-11 e5. https://doi.org/10.1016/j.celrep.2019.02.063.

102. Yi HG, Jeong YH, Kim Y, Choi YJ, Moon HE, Park SH, et al. A bioprinted human-glioblastoma-on-a-chip for the identification of patient-specific responses to chemoradiotherapy. Nat Biomed Eng. 2019;3(7):509-19. https://doi.org/10.1038/s41551-019-0363-x.

103. Miyai $M$, Tomita $H$, Soeda $A$, Yano $H$, Iwama $T$, Hara A. Current trends in mouse models of glioblastoma. J Neuro-Oncol. 2017;135(3):423-32. https:// doi.org/10.1007/s11060-017-2626-2.

104. Wouters R, Bevers S, Riva M, De Smet F, Coosemans A. Immunocompetent Mouse Models in the Search for Effective Immunotherapy in Glioblastoma. Cancers. 2020;13(1):19. https://doi.org/10.3390/cancers13010019.

105. lorgulescu JB, Gokhale PC, Speranza MC, Eschle BK, Poitras MJ, Wilkens MK, et al. Concurrent dexamethasone limits the clinical benefit of immune checkpoint blockade in glioblastoma. Clin Cancer Res. 2020;21(1):276-87. https://doi.org/10.1158/1078-0432.CCR-20-2291.

\section{Publisher's Note}

Springer Nature remains neutral with regard to jurisdictional claims in published maps and institutional affiliations. 